\title{
The wobble hypothesis revisited: Uridine-5-oxyacetic acid is critical for reading of $\mathrm{G}$-ending codons
}

\author{
S. JOAKIM NÄSVALL, PENG CHEN, ${ }^{1}$ and GLENN R. BJÖRK \\ Department of Molecular Biology, Umeå University, S-901 87 Umeå, Sweden
}

\begin{abstract}
According to Crick's wobble hypothesis, tRNAs with uridine at the wobble position (position 34) recognize A- and G-, but not $\mathrm{U}$ - or C-ending codons. However, $U$ in the wobble position is almost always modified, and Salmonella enterica tRNAs containing the modified nucleoside uridine-5-oxyacetic acid $\left(\mathrm{cmo}^{5} \mathrm{U} 34\right)$ at this position are predicted to recognize $U$ - (but not C-) ending codons, in addition to A- and G-ending codons. We have constructed a set of S. enterica mutants with only the $\mathrm{cmo}^{5} \mathrm{U}$-containing tRNA left to read all four codons in the proline, alanine, valine, and threonine family codon boxes. From the phenotypes of these mutants, we deduce that the proline, alanine, and valine tRNAs containing $\mathrm{cmo}^{5} \mathrm{U}$ read all four codons

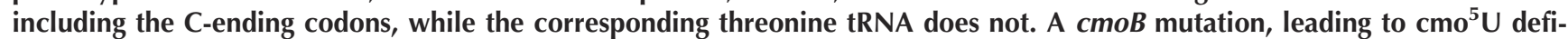
ciency in tRNA, was introduced. Monitoring A-site selection rates in vivo revealed that the presence of $\mathrm{cmo}^{5} \mathrm{U} 34$ stimulated the reading of CCU and CCC (Pro), GCU (Ala), and GUC (Val) codons. Unexpectedly, $\mathbf{c m o}^{5} \mathrm{U}$ is critical for efficient decoding of G-ending Pro, Ala, and Val codons. Apparently, whereas G34 pairs with $U$ in mRNA, the reverse pairing (U34-G) requires a modification of U34.
\end{abstract}

Keywords: wobble hypothesis; translation; tRNA; modified nucleoside; decoding

\section{INTRODUCTION}

The genetic message is read by tRNAs that decode one triplet at a time. Of the 64 codons, 61 are sense codons and represent an amino acid in the final protein. Triplets with the same first two nucleosides constitute a codon box, and if all four codons represent one amino acid, such a box is called a family codon box. In all organisms there are eight family codon boxes (Fig. 1, shaded), and in Salmonella enterica serovar Typhimurium, six of them are decoded by tRNAs of which one has uridine-5-oxyacetic acid (cmo ${ }^{5} \mathrm{U} 34$ ) or its methylester $\left(\mathrm{mcmo}^{5} \mathrm{U} 34\right)$ in position 34 (the wobble position) (Fig. 2). These six family codon boxes are specific for leucine, valine, serine, proline, threonine, and alanine (Fig. 1, light shade). To read the four codons in such a family codon box, there are, besides the $\mathrm{cmo}^{5} \mathrm{U} 34$-containing tRNA, one (valine and alanine) or two (leucine, serine,

\footnotetext{
${ }^{1}$ Present address: Department of Forest Genetics and Plant Physiology, Swedish University of Agricultural Sciences, S-901 83 Umeå, Sweden.

Reprint requests to: Glenn R. Björk, Department of Molecular Biology, Umeå University, S-90187 Umeå, Sweden; e-mail: glenn.bjork@molbiol. umu.se; fax: 4690772630.

Article published online ahead of print. Article and publication date are at http://www.rnajournal.org/cgi/doi/10.1261/rna.731007.
}

threonine, and proline) additional isoacceptor tRNAs. One of these isoacceptors has $\mathrm{G}$ as the wobble nucleoside, and in four boxes (leucine, proline, threonine, and serine) the third isoacceptor has $\mathrm{C}$ as the wobble nucleoside (Fig. 1). According to the wobble hypothesis (Crick 1966), G34 base-pairs with $\mathrm{C}$ and $\mathrm{U}$ as the third nucleoside of the codon [denoted C(III) and U(III)], whereas C34 only basepairs with $\mathrm{G}(\mathrm{III})$. Uridine as the wobble nucleoside cannot interact with a pyrimidine in the mRNA, since two pyrimidines are too "short" to form a base pair. Therefore, it was thought that the G34-containing tRNAs are essential for decoding the $\mathrm{U}$ - and $\mathrm{C}$-ending codons. However, $\mathrm{U}$ as the wobble nucleoside is almost always modified, and the $\mathrm{cmo}^{5}$ modification and the related modification 5-methoxyuridine, $\mathrm{mo}^{5} \mathrm{U}$, present in tRNA of Bacillus subtilis, is predicted to extend the wobble capacity to read not only A(III) and G(III), as predicted by the wobble hypothesis, but also U(III), but not C(III) (Yokoyama et al. 1985). Thus, the G34-containing tRNAs seems to be required to decode the C-ending codons in these family codon boxes. Most in vitro experiments with Escherichia coli tRNAs or anticodon stem-loops (ASLs) support the theoretical considerations that a $U$ reads $A(I I I)$ and $G\left(\right.$ III) and that $c \mathrm{cmo}^{5} \mathrm{U}$ enhances the wobble to include U(III), but not C(III) (Oda 


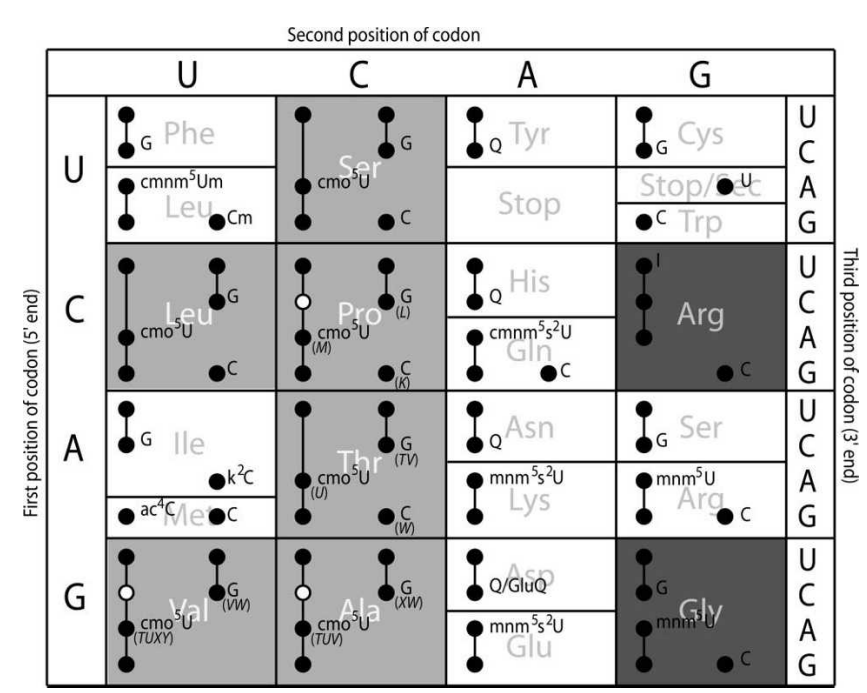

FIGURE 1. The genetic code. The eight codon boxes with shaded background are the family codon boxes, containing four codons encoding one amino acid (fourfold degenerate). The six lightershaded boxes contain tRNAs having $\mathrm{cmo}^{5} \mathrm{U}$ as wobble nucleoside. The boxes with white background are the mixed codon boxes. A circle corresponds to a codon read by a tRNA, and a line connecting two or more circles indicates that the same tRNA is able to read those codons. Filled circles indicate codon reading as predicted by the wobble hypothesis (Crick 1966) or the revised wobble rules (Yokoyama et al. 1985). Open circles indicate that those tRNAs are able to read also the C-ending codons (results presented in this study and in Näsvall et al. 2004). Next to the symbol for each tRNA is indicated which wobble nucleoside it contains. The letters within parentheses below the wobble nucleoside in the family boxes for proline, threonine, alanine, and valine indicate the last letter in the name of the genes encoding the corresponding tRNAs (e.g., tRNA $\mathrm{C}_{\mathrm{cmo5}}^{\mathrm{Val}}$ ic is encoded by the four genes valT, valU, valX, and valY, and tRNA ${ }_{\mathrm{GGG}}^{\mathrm{Pro}}$ is encoded by the gene proL).

et al. 1969; Ishikura et al. 1971; Mitra et al. 1979; Samuelsson et al. 1980; Takai et al. 1999; Phelps et al. 2004; Sørensen et al. 2005).

In contrast to the above-mentioned results obtained in vitro, there is evidence from in vivo experiments that $\mathrm{cmo}^{5} \mathrm{U} 34$-containing tRNAs base-pair also with C(III). A strain that lacks the G34-containing tRNA ${ }_{\mathrm{GGG}}^{\text {Pro }}$ (the subscript indicates the sequence of the anticodon in the $5^{\prime} \rightarrow 3^{\prime}$ direction) and the C34-containing tRNA $\mathrm{CGG}_{\mathrm{CG}}^{\mathrm{Pro}}$ and thus only has the $\mathrm{cmo}^{5} \mathrm{U} 34$-containing $\mathrm{RRNA}_{\mathrm{cmos}}^{\mathrm{Pro}} \mathrm{PGG}^{\mathrm{P}}$ is viable, demonstrating that $\mathrm{RNA}_{\text {cmo5UGG with }}^{\text {Pro }} \mathrm{cmo}^{5} \mathrm{U} 34$ as the wobble nucleoside can read all four proline codons (Näsvall et al. 2004). Based on a synergistic growth defect in mutants that lack $\mathrm{RNA}_{\mathrm{GGG}}^{\mathrm{Pro}}$ and are hypo-modified in the wobble position of $\mathrm{TRNA}_{\mathrm{cmo5UGG}}^{\mathrm{Pro}}$, the presence of $\mathrm{cmo}^{5} \mathrm{U} 34$ was suggested to promote an efficient reading of $\mathrm{C}$ - and $\mathrm{U}$ ending proline codons (Näsvall et al. 2004). Similarly, a strain having only tRNA $\mathrm{Ala}$ cmosGC with $\mathrm{cmo}^{5} \mathrm{U} 34$ as the wobble nucleoside is also viable (Gabriel et al. 1996). It was recently shown that the binding of tRNA $\mathrm{cmosuGC}_{\mathrm{Ala}}^{\mathrm{Ala}}$ GCC codons is only slightly weaker than binding to GCA, and that the kinetics of A-site binding at GCC is within the range for cognate interactions (Kothe and Rodnina 2007). Thus, at least $\mathrm{tRNA}_{\mathrm{cmo5UGG}}^{\text {Pro }}$ and $\mathrm{tRNA}_{\mathrm{cmo5UGC}}^{\mathrm{Ala}}$ are able to read codons ending with $\mathrm{C}(\mathrm{III})$, contrary to the theory and to most results obtained in vitro. However, the impact of $\mathrm{cmo}^{5} \mathrm{U} 34$ on decoding by $\mathrm{RNA}_{\mathrm{cmo5UGC}}^{\mathrm{Ala}}$ was not addressed by Gabriel et al. (1996) or Kothe and Rodnina (2007), since their analysis was performed with fully modified tRNA $\mathrm{Amo5UGC}_{\text {cla }}$ (Gabriel et al. 1996; Kothe and Rodnina 2007). Here, we extend these studies to elucidate whether the $\mathrm{cmo}^{5} \mathrm{U} 34$-containing tRNAs specific for valine and threonine are also able to read the four codons in the corresponding family boxes and if the presence of $\mathrm{cmo}^{5} \mathrm{U} 34$ is required for such a reading in the family codon boxes specific for valine, alanine, and threonine.

To study the function of $\mathrm{cmo}^{5} \mathrm{U} 34$ in vivo, we need a way to manipulate the presence of $\mathrm{cmo}^{5} \mathrm{U} 34$ in tRNA. We have recently identified two genes $(\mathrm{cmo} A$ and $B$ ) whose products are required for the synthesis of $\mathrm{cmo}^{5} \mathrm{U} 34$ (Näsvall et al. 2004). Deletion of the $c m o B$ gene results in a complete absence of $\mathrm{cmo}^{5} \mathrm{U} 34$ in tRNA, and all of the $\mathrm{cmo}^{5} \mathrm{U}$ found in the wild type is present as the biosynthetic intermediate 5-hydroxyuridine (ho ${ }^{5} \mathrm{U}$ ) (Fig. 2; Näsvall et al. 2004). Therefore, we have changed the allelic state of the $\mathrm{cmoB}$ gene in our attempt to demonstrate the coding capacities of $\mathrm{cmo}^{5} \mathrm{U}$ versus $\mathrm{ho}{ }^{5} \mathrm{U}$ in tRNAs specific for proline, alanine, and valine. Surprisingly, considering the wobble hypothesis and other predictions (Crick 1966; Yokoyama et al. 1985), our results show that $\mathrm{cmo}^{5} \mathrm{U}$ is required for efficient decoding of G-ending codons by tRNA $A_{c m o 5 U G C}^{\mathrm{Ala}} \mathrm{tRNA}_{\mathrm{c}-}^{\mathrm{Val}}$

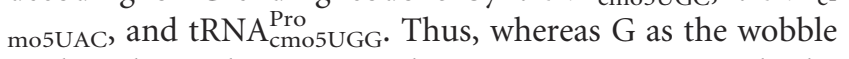
nucleoside can base-pair with $U$ in mRNA, apparently the reverse pairing $[\mathrm{U} 34-\mathrm{G}(\mathrm{III})]$ requires a modification of uridine.

\section{RESULTS}

\section{tRNA ${ }_{\text {cmo5UGU }}^{\text {Thr }}$ containing $\mathrm{cmo}^{5} \mathrm{U} 34$ cannot read all four threonine codons}

S. enterica has three threonine isoacceptors ( $\mathrm{tRNA}_{\mathrm{cmo5UGU}}^{\mathrm{Thr}}$ tRNA $_{\mathrm{GGU}}^{\mathrm{Thr}}$, and tRNA ${ }_{\mathrm{CGU}}^{\mathrm{Thr}}$ ) (see Fig. 1). The G34-containing $\mathrm{tRNA}_{\mathrm{GGU}}^{\mathrm{Thr}}$ is encoded by the genes thrT and thr $V$ and the C34-containing tRNA $\mathrm{CGU}_{\mathrm{CGr}}^{\mathrm{Thr}}$ is encoded by the gene thrW (Fig. 3A). Strains lacking the genes encoding tRNA $\mathrm{GGH}_{\mathrm{GG}}^{\mathrm{Th}}$ and tRNA $_{\mathrm{CGU}}^{\mathrm{Thr}}$ were constructed by inserting a kanamycin resistance cassette flanked by FLP recombinase target sequences (FRTs) (Datsenko and Wanner 2000) into the thrT, thrV, or thrW genes. The three resulting single mutants lacking either the C34-containing tRNA $\mathrm{CGGU}_{\mathrm{Ch}}$ or one of the two genes encoding the G34-containing tRNA ${ }_{\mathrm{GGU}}^{\mathrm{Thr}}$ were all viable, with no apparent growth phenotype on solid rich medium at $37^{\circ} \mathrm{C}$ (data not shown).

To test if $\mathrm{tRNA}_{\mathrm{cmo5UGU}}^{\mathrm{Thr}}$ is able to read all four threonine codons, we attempted to generate a mutant having $\mathrm{tRNA}_{\mathrm{cmo5UGU}}^{\mathrm{Thr}}$ as the only remaining threonine isoacceptor 


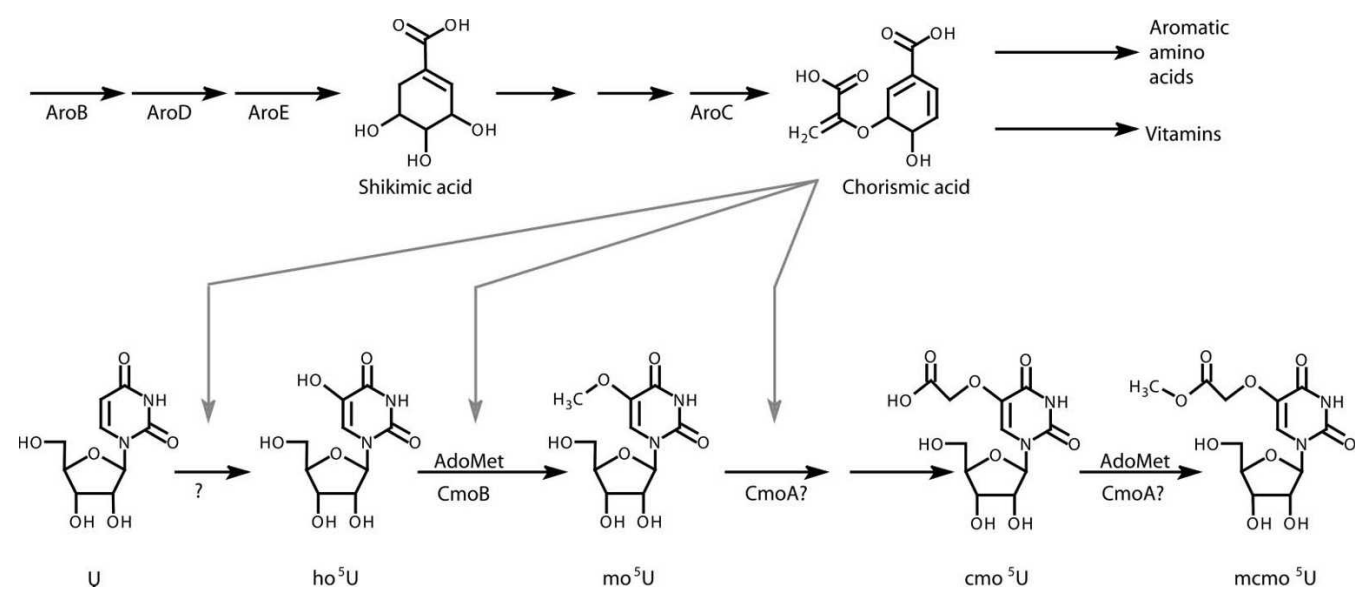

FIGURE 2. The proposed biosynthetic pathway for the synthesis of $\mathrm{cmo}^{5} \mathrm{U}$ and $\mathrm{mcmo}^{5} \mathrm{U}$. (Gray arrows) Indicate the link between chorismic acid (or an unknown derivative of it) and different steps in the synthesis of $\mathrm{cmo}^{5} \mathrm{U}$ according to Näsvall et al. (2004). (U) Uridine; (ho ${ }^{5} \mathrm{U}$ ) 5hydroxyuridine; $\left(\mathrm{mo}^{5} \mathrm{U}\right)$ 5-methoxyuridine; $\left(\mathrm{cmo}^{5} \mathrm{U}\right)$ uridine-5-oxyacetic acid; ( $\left.\mathrm{mcmo}^{5} \mathrm{U}\right)$ uridine-5-oxyacetic acid methyl ester. (Adapted from Näsvall et al. 2004 and reprinted with permission from the RNA Society (C2004.)

by deleting the two genes encoding the G34-containing tRNA $\mathrm{ThGU}_{\mathrm{GG}}(\operatorname{thr} T$ and $V$ ) and the C34-containing tRNA $\mathrm{Thr}$ $(t h r W)$. Whereas construction of mutants with one remaining gene encoding the G34-containing tRNA $\mathrm{GG}$ Thr was possible, combining mutations in both genes encoding this tRNA failed (Table 1). These results suggest that a double mutant (thrT thrV) having only the $\mathrm{cmo}^{5} \mathrm{U} 34$ - and C34containing threonine isoacceptors is not viable and consequently indicates that $\mathrm{tRNA}_{\mathrm{GGU}}^{\mathrm{Thr}}$ is essential. Still, a few transductants appeared in the attempts to make the thrT $\operatorname{thr} V$ double mutant. Since it is known that in a growing culture of Salmonella, different loci can be transiently duplicated, the rare $\mathrm{Km}^{\mathrm{R}}$ transductants may have both the wild-type allele and the mutated allele of thrT or thrV. Indeed, all of the 37 tested transductants possessed both the wild-type and the thrT<>kan alleles. Moreover, purification of 10 different $\mathrm{Km}^{\mathrm{R}}$ transductants on nonselective plates revealed segregation of $\mathrm{Km}^{\mathrm{R}}$ and $\mathrm{Km}^{\mathrm{S}}$ clones as expected if the original transductant contains a duplication of the wild-type and the thrT<>kan alleles. We conclude that the G34-containing tRNA $\mathrm{GGr}$ is essential, most likely because the $\mathrm{cmo}^{5} \mathrm{U} 34$-containing $\mathrm{tRNA}_{\mathrm{cmos} \text { UGU }}^{\mathrm{Thr}}$ cannot recognize $\mathrm{C}$-ending threonine codons.

\section{The $\mathrm{cmo}^{5} \mathrm{U}$-containing tRNA $\mathrm{cmo5UAC}_{\mathrm{Val}}^{\mathrm{Val}}$ by itself can only support growth at an extremely reduced rate}

The two genes valV and valW, encoding two slightly different $t \mathrm{RNA}_{\mathrm{GAC}}^{\mathrm{Val}} \mathrm{s}$, are present as a tandem repeat in a dicistronic operon with no other genes (Fig. 3B). A mutant $(\Delta$ valVW) lacking tRNA $\mathrm{Gal}$, and thus having only the $\mathrm{cmo}^{5} \mathrm{U}$-containing tRNA $\mathrm{cmos}_{\mathrm{VAC}}^{\mathrm{Val}}$ to read the four valine codons (Fig. 1), was viable but showed a $70 \%$ reduction in growth rate (Table 2 ). These results indicate that, similarly

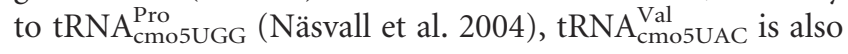

able to read all four valine codons, albeit with low efficiency.

As earlier reported, $c m o B$ mutants have ho ${ }^{5} \mathrm{U} 34$ instead of $\mathrm{cmo}^{5} \mathrm{U} 34$ in their tRNA (Näsvall et al. 2004). To test the impact of such hypo-modification on the decoding capacity of tRNA $\mathrm{Cal}_{\mathrm{cmo5UAC}}$, we disrupted the $c m o B$ gene in a strain lacking the G34-containing tRNA $\mathrm{Gal}$. This strain is viable but showed a decrease in growth rate compared to the parent strain (Table 2), and it also accumulated fastergrowing suppressor mutants (data not shown). In addition to the slow-growth phenotype, cultures sometimes formed visible aggregates, which were caused by part of the population of cells forming long filaments (data not shown). Clearly, the presence of the $\mathrm{cmo}^{5}$-modification improves the decoding efficiency of $\mathrm{TRNA}_{\text {cmosuAC. }}^{\mathrm{Val}}$

To test if increased levels of tRNA mutants lacking tRNA ${ }_{\mathrm{GAC}}^{\mathrm{Val}}$ and $\mathrm{cmo}^{5} \mathrm{U}$, we compared the growth of strains harboring either plasmid p815 (O'Connor 2002) (carrying the E. coli valU operon, containing three genes encoding $\mathrm{TRNA}_{\mathrm{cmo5} \mathrm{VAC}}^{\mathrm{Val}}$ and one gene encoding tRNA $\mathrm{mnm}_{\mathrm{m} 5 \mathrm{~s} 2 \mathrm{UUU}}^{\mathrm{Ly}}$ ) or plasmid pLG339 (vector control). Overexpression of $\mathrm{RNA}_{\mathrm{cmoSUAC}}^{\mathrm{Val}}$ partially suppressed the growth phenotypes of the strains having only this tRNA (Fig. 4). Also, overexpression of the hypo-modified tRNA $\mathrm{ha5}$ Val mutant, demonstrating that $\mathrm{tRNA}_{\text {cmo5UAC }}^{\mathrm{Val}}$ at normal concentration is, indeed, dependent on the $\mathrm{cmo}^{5}$-modification.

In order to further study the efficiency of tRNA $\mathrm{cmosUAC}_{\mathrm{Val}}^{\mathrm{Val}}$ in reading the four valine codons and the effect of having ho ${ }^{5} \mathrm{U}$ in place of $c o^{5} \mathrm{U}$, we used the system described by Curran and Yarus (1989) to measure the in vivo A-site selection rates (Fig. 5). The mutant lacking both $\mathrm{RNA}_{\mathrm{GAC}}^{\mathrm{Val}}$ and $\mathrm{cmo}^{5} \mathrm{U}(\Delta$ valvW $c$ moB2 $<>f r t)$ was not included because of difficulties in keeping the culture suppressor free, but also because of the filamentous growth phenotype, 
A
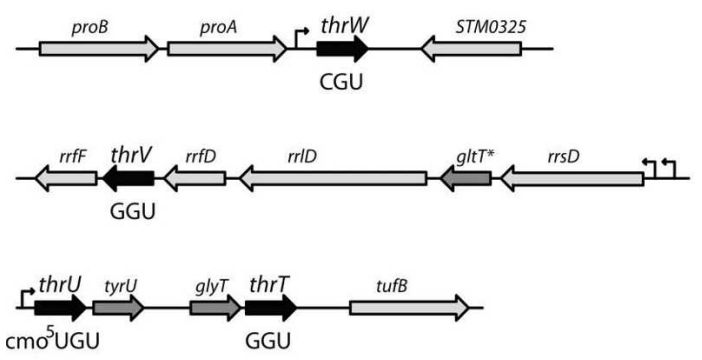

C
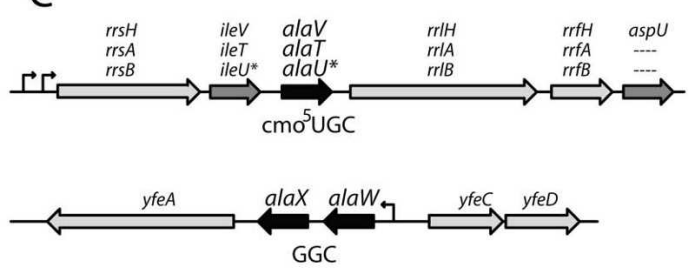

B
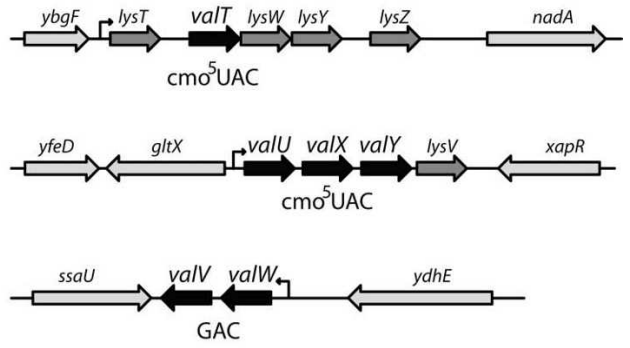

D

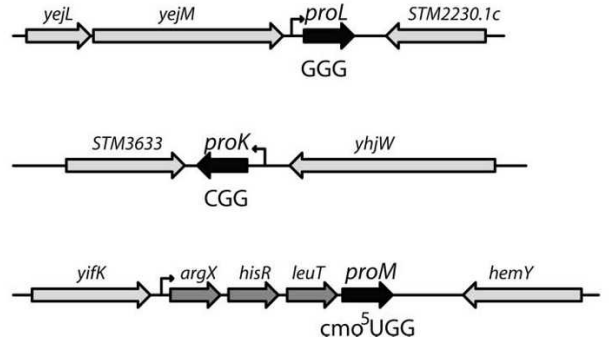

FIGURE 3. Locations of tRNA genes in the S. enterica genome. (A) Threonine tRNAs. (Upper line) The thrW gene, encoding tRNA line) The $r r n D$ rRNA operon containing one of the two genes encoding tRNA $\mathrm{ThGU}_{\mathrm{Gr}}^{\mathrm{Thr}}$. (Lower line) The tufB operon, containing the gene encoding tRNA $_{\mathrm{cmo5UGC}}^{\mathrm{Thr}}$ as well as the second gene encoding tRNA $\mathrm{GGU}_{\mathrm{GH}}^{\mathrm{Thr}}$ (B) Valine tRNA genes. (Upper and middle lines) The two tRNA operons containing the four genes encoding tRNA $\mathrm{cmo5 \textrm {UAC }}$. (Lower line) The dicistronic valv, valW operon containing the two genes encoding tRNA $\mathrm{GAC}$. (C) Alanine

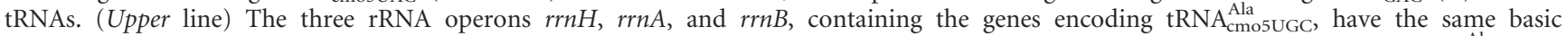
organization except an additional tRNA gene $(a s p U)$ at the end of $r r H$. (Lower line) The alaW, alaX tRNA operon encoding tRNA Ala $(D)$ Proline isoacceptors. (Upper line) The monocistronic proL gene, encoding tRNA $\mathrm{GGG}$. (Middle line) The proK gene, encoding tRNA $\mathrm{CGG}$. (Lower line) The operon containing the gene encoding $\operatorname{tRNA}_{\text {cmosUGG }}^{\text {Pro }}$ as well as three other tRNA genes. (Black arrows) tRNA genes encoding threonine, valine, alanine, or proline tRNAs; (dark gray arrows) other tRNA genes; (light gray arrows) other genes. The anticodons of the relevant tRNAs are

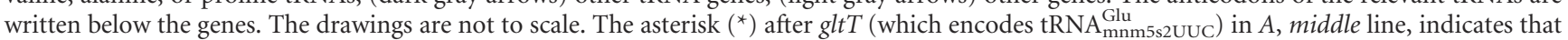
the gene (STM3397) is not named in Salmonella. gltT is the name of an identical gene in the E. coli rrnB operon, which in Salmonella instead contains the genes ile $U$ and alaU (asterisks in $C$ ).

which would produce unreliable OD values. As expected, the rate of A-site selection is severely reduced at all four codons in the strain lacking the G34-containing tRNA $\mathrm{Gal}$ (Fig. 5). Most severely affected was the rate at the GUC codon. This is not surprising considering the fact that this strain lacks the tRNA (tRNA $\mathrm{Val}_{\mathrm{GAC}}^{\mathrm{al}}$ ) that is the major tRNA recognizing GUC codons. The data show the relative efficiency of fully modified $\mathrm{RRNA}_{\mathrm{cmos} \mathrm{UaC}}^{\mathrm{Val}}$ at recognizing the different codons; it recognized GUA, GUU, and GUG with equal efficiency, while, as expected, it was quite poor

TABLE 1. The $\mathrm{cmo}^{5} \mathrm{U}$-containing tRNA $\mathrm{Cm}_{\mathrm{cmo}}^{\mathrm{Th}} \mathrm{UGU}$ is unable to decode all four threonine codons

\begin{tabular}{|c|c|c|c|}
\hline $\begin{array}{l}\text { Donor genotype } \rightarrow \\
\text { Recipient genotype } \downarrow\end{array}$ & $\begin{array}{l}t h r T<>k a n^{\mathrm{a}} \\
\quad(\mathrm{G} 34)\end{array}$ & $\begin{array}{l}\text { thrV }<>k a n^{\mathrm{a}} \\
\quad(\mathrm{G} 34)\end{array}$ & $\begin{array}{c}\text { thrW } \quad>k^{2} a n^{\mathrm{a}} \\
(\mathrm{C} 34)\end{array}$ \\
\hline $\mathrm{LT}^{\mathrm{a}}$ & $1.0(2388)^{\mathrm{C}}$ & $1.0(\sim 4700)^{\mathrm{C}}$ & $1.0(1954)^{c}$ \\
\hline$t h r T<>$ frt $(\mathrm{G} 34)^{\mathrm{a}}$ & $0.95(2276)^{\mathrm{c}}$ & $6.4 \times \mathbf{1 0}^{-4}(3)^{c}$ & $0.99(1934)^{c}$ \\
\hline thrV $<>$ frt $(\mathrm{G} 34)^{\mathrm{a}}$ & $8.4 \times \mathbf{1 0}^{-3}\left(20^{b}\right)^{c}$ & $1.2(\sim 5500)^{\mathrm{C}}$ & $0.91(1786)^{c}$ \\
\hline thrW $<>$ frt $(\mathrm{C} 34)^{\mathrm{a}}$ & $0.90(2157)^{\mathrm{c}}$ & $1.1(5224)^{\mathrm{C}}$ & $0.92(1807)^{c}$ \\
\hline
\end{tabular}

${ }^{\text {aP2} 2}$ transductions designed to construct mutants lacking both genes encoding the G34-containing tRNA Ghr $_{\text {(thr }}$ (th and thrT). Mutants carrying alleles disrupted with $\mathrm{Km}^{\mathrm{R}}$ cassettes (indicated by $<>\mathrm{kan}$ ) were used as donors, and mutants with disrupted alleles without resistance cassettes (indicated by $<>$ frt) were used as recipients. Strain LT2 (wild-type) and strains lacking the C34-containing tRNA Chr (encoded by thrW) were used as controls. For each individual transduction, the same volume of phage lysate was used.

${ }^{\mathrm{b} S e v e n ~ c o l o n i e s ~ w e r e ~ v i s i b l e ~ a f t e r ~} 24 \mathrm{~h}$ of incubation at $37^{\circ} \mathrm{C}$. Thirteen more colonies appeared during the following $48 \mathrm{~h}$.

'Shown are frequencies of transduction relative to the frequency obtained when LT2 was used as recipient. The numbers within parentheses are the actual numbers of $\mathrm{Km}^{\mathrm{R}}$ transductants. Numbers in boldface show the combinations that gave a significantly lower frequency of transduction. 
TABLE 2. $\mathrm{tRNA}_{\mathrm{cmo5UAC}}^{\mathrm{Val}}$ by itself supports growth at an extremely reduced rate

\begin{tabular}{|c|c|c|c|}
\hline Genotype & $\begin{array}{l}\text { Anticodons } \\
\text { present }\end{array}$ & $\begin{array}{l}\text { Specific growth } \\
\text { rate } k\left(h^{-1}\right)\end{array}$ & $\begin{array}{l}\text { Relative change } \\
\left(k-k_{\mathrm{LT} 2}\right) / k_{\mathrm{LT} 2}\end{array}$ \\
\hline Wt (LT2) & GAC $\mathrm{cmo}^{5} \mathrm{UAC}$ & $1.79 \pm 0.021^{\mathrm{a}}$ & 0.00 \\
\hline $\mathrm{cmoB2}$ & GAC ho ${ }^{5}$ GU & $1.82 \pm 0.041^{\mathrm{a}}$ & 0.02 \\
\hline$\Delta v a / V W$ & $\mathrm{cmo}^{5} \mathrm{UGU}$ & $0.53 \pm 0.028^{b, c}$ & -0.70 \\
\hline $\begin{array}{l}\Delta \text { valVW } \\
\text { cmoB2 }\end{array}$ & ho ${ }^{5}$ GU & $0.34 \pm 0.006^{b, d}$ & -0.81 \\
\hline
\end{tabular}

${ }^{a}$ The values are averages from two or three dilutions from two separate cultures (LT2) or only from two dilutions from one culture (cmoB2).

${ }^{\mathrm{b}}$ During growth, samples were taken to check for the presence of faster-growing suppressor mutants. The cultures used for these calculations all contained $<5 \%$ suppressors at the end of the experiment. ${ }^{\mathrm{c}}$ The values are averages calculated from five separate cultures. We do not consider these cultures to have been in balanced growth (See Materials and Methods).

dOwing to difficulties keeping pure cultures of this strain, this value is calculated from only two different cultures grown on separate days. We do not consider these cultures to have been in balanced growth (See Materials and Methods).

at recognizing the GUC codon. Whereas the cmoB2 mutation did not influence the rate of valyl-tRNA ${ }^{\mathrm{Val}}$ selection to the GUU- and GUA-programmed ribosomal A-site (Fig. 5), significant decreases in the rates at GUC and, unexpectedly, also at GUG codons were observed.

\section{tRNA ${ }_{\text {cmo5UGC }}^{\mathrm{Ala}}$ requires $\mathrm{cmo}^{5} \mathrm{U} 34$ for efficient wobble reading of GCG}

The two identical genes alaX and alaW (sometimes referred to as ala $W_{\alpha}$ and ala $W_{\beta}$ ) (Fig. 3C) encoding tRNA $\mathrm{Ala}_{\mathrm{GGC}}$, are arranged as a tandem repeat in a single operon containing no other genes. A strain lacking tRNA $\mathrm{Gla}_{\mathrm{GGC}}^{\mathrm{Ala}}(\Delta a l a X W)$ is viable, as is also the case in E. coli (Gabriel et al. 1996), but has a clear reduction in growth rate compared to the wildtype strain (LT2) (Table 3), a phenotype that is further enhanced at higher temperature, seen as a decreased colony size on plates at $44^{\circ} \mathrm{C}$ (data not shown). These results indicate that, similarly to $\mathrm{tRNA}_{\mathrm{cmo5UGG}}^{\text {Pro }}$ (Näsvall et al. 2004), $\mathrm{tRNA}_{\text {cmo5UGC }}^{\mathrm{Ala}}$ is able to read all four alanine codons, although not efficiently enough to support a maximum growth rate.

When $c m o B<>k a n$ was transduced into a strain $(\Delta$ alaXW) lacking tRNA $\mathrm{Ala}$, tiny colonies (barely visible without magnification) started to appear after $2 \mathrm{~d}$ of incubation at $37^{\circ} \mathrm{C}$. A few larger colonies $(\sim 0.2 \%$ of totally 409 transductants in one transduction) were also apparent, indicating the presence of suppressor mutants in some colonies. The "tiny" colonies were purified on selective medium and found to be viable but to accumulate suppressor mutations that partially restored growth (Fig. 6). When we transduced a wild-type strain (LT2) with the same amount of the same phage lysate, we received about the same number of transductants as when strain GT7365 $(\triangle a l a X W)$ was used as recipient, but the obtained transductants showed a normal growth phenotype. These results show that a mutant lacking tRNA $\mathrm{GGC}$ is viable even when it is hypo-modified at the wobble position in the only remaining alanine tRNA, but it has an extremely reduced growth rate, and mutations that partially restore growth are relatively frequent. If the growth phenotype would be caused by poor reading of one or more of the alanine codons, expression of more of the hypo-modified tRNA cmo5UGC $_{\text {Ala }}$ would allow the mutant to grow faster. To test this, we introduced the $c m o B 2<>k a n$ allele into strains harboring plasmid p70 (Vila-Sanjurjo et al. 1999), carrying E. coli genes encoding $\mathrm{RNAA}_{\text {cmosUGC }}^{\mathrm{Ala}}$ and four other tRNAs (tRNA $A_{\mathrm{QUC}}^{\mathrm{Asp}}, \mathrm{tRNA}_{\mathrm{CCA}}^{\mathrm{Trp}}, \mathrm{tRNA} \mathrm{GAU}_{\mathrm{G}}^{\mathrm{Il}}$, and tRNA $\mathrm{GGU}_{\mathrm{GG}}^{\mathrm{Thr}}$ ) expressed from the tac promoter. The growth phenotypes (seen as relative colony sizes on plates) of these strains were compared to the corresponding plasmid-free strains (Fig. 6). The relatively mild growth defect of the $\Delta$ alaXW strain, which has only the $\mathrm{cmo}^{5} \mathrm{U} 34$-containing alanine tRNA, seems to be fully suppressed, and the $\triangle a$ a $a X W$ cmoB2 $<>$ kan mutant is partially suppressed by overexpression of $\mathrm{tRNA}_{\mathrm{cmo5UGC}}^{\mathrm{Ala}}$. Thus tRNA $\mathrm{Amo5UGC}_{\mathrm{Ala}}^{\mathrm{Ala}}$, when expressed at normal levels, is very dependent on the presence of the modification for its ability to read some of the four codons, but less so if it is overexpressed. We also measured the Asite selection rate at the four alanine codons. The $\Delta$ alaXW cmoB2 mutant was considered too slow growing and unstable to be included in such an analysis. The cmoB2 mutant shows a large reduction in the rate of reading the

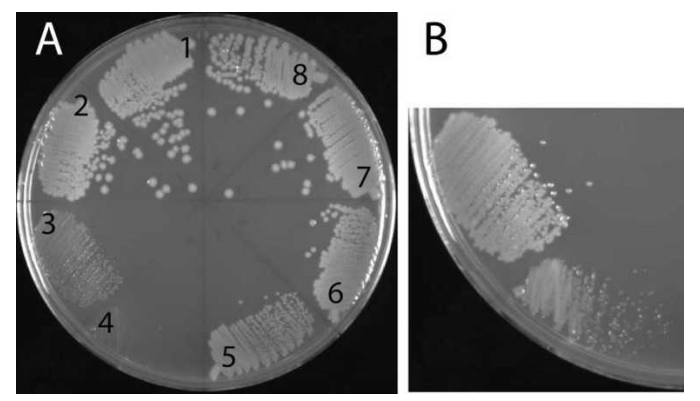

FIGURE 4. Overexpression of $\mathrm{RNA}_{\mathrm{cmoSUAC}}^{\mathrm{Val}}$ restores growth of a $\Delta$ valvW mutant. (A) Growth after $25 \mathrm{~h}$ of incubation at $37^{\circ} \mathrm{C}$. (Sectors 1-4) Strains carrying pLG339 (vector control); (sectors 5-8) strains carrying p815 (valU valX valY lysV). The chromosomal genotypes are (1,8) LT2 (wt); (2,7) cmoB2<>cat; (3,6) $\Delta$ valVW; $(4,5) \Delta$ valVW cmoB2<>cat. (B) Sectors 3 and 4 of the same plate as in $A$, but after $44 \mathrm{~h}$ at $37^{\circ} \mathrm{C}$. No suppressor mutants were apparent in this particular experiment. The relative colony sizes after $15 \mathrm{~h}$ of growth were (LT2/pLG339 and cmoB2/pLG339) $1.0 \pm 0.03$; (LT2/ p815) $1.0 \pm 0.07 ;(\mathrm{cmoB} 2 / \mathrm{p} 815) 1.0 \pm 0.03 ;(\Delta$ valVW/p815) $0.68 \pm$ 0.04 . Colonies of $\Delta v a l V W \mathrm{cmoB} 2 / \mathrm{p} 815$ were visible but still too small to measure, and no colonies were visible of $\Delta$ valVW/pLG339 or $\Delta$ valVW cmoB2/pLG339. After $25 \mathrm{~h}$, colonies of $\Delta$ valVW cmoB2/p815 were $\sim 30 \%$ smaller than $\Delta v$ valVW/p 815 , and after $44 \mathrm{~h},(B)$ colonies of $\Delta$ valVW cmoB2/pLG339 were approximately half the size compared to $\Delta$ valVW/pLG339. 


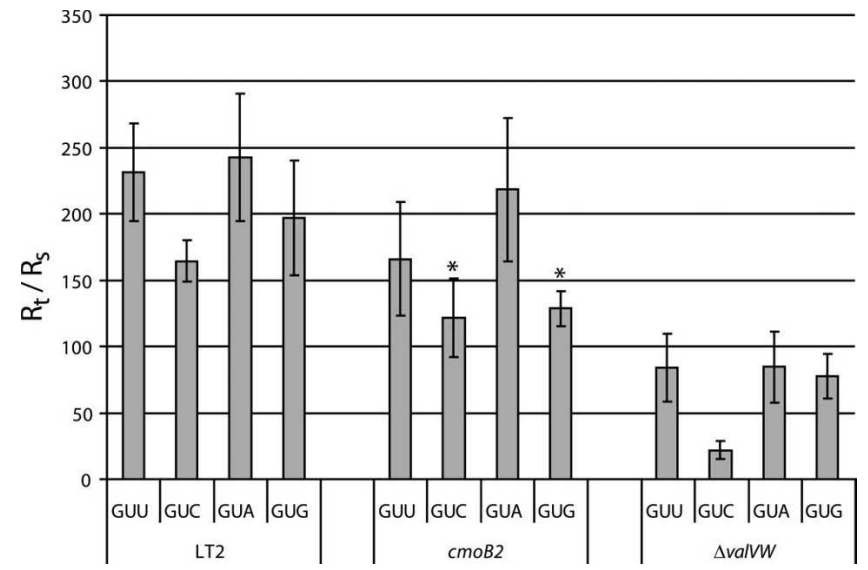

FIGURE 5. A-site selection rates at valine (GUN) codons. $\left.{ }^{*}\right)$ Values in the $c m o B 2$ mutant are significantly different from the control (LT2), as determined by a student's $t$-test (two sample, equal variance, $p<0.05)$. All values for the $\Delta$ valVW mutant are significantly different from LT2 $(p<0.005)$. The values are averages of four experiments, with at least two independent cultures of each strain.

GCG codon (Fig. 7). The $\Delta$ alaXW mutant has a reduction in the rate of alanyl-tRNA entry on all four codons, and the most severe reduction is on the GCC codon. Taken together, these results show that fully modified tRNA cmo5UGC $_{\text {Ala }}$ reads GCA, GCG, and GCU efficiently and GCC poorly and that $\mathrm{cmo}^{5} \mathrm{U}$ improves reading of the G-ending codon.

\section{$\mathrm{cmo}^{5} \mathrm{U} 34$ in $\mathrm{TRNA} \mathrm{A}_{\mathrm{cmo5UGG}}^{\text {Pro }}$ mainly enhances wobble reading of $G$}

A mutant having only the $\mathrm{cmo}^{5} \mathrm{U}_{\text {-contatining }} \mathrm{RNAA}_{\text {cmosUGG }}^{\text {Pro }}$ is viable without any apparent phenotype, demonstrating that this tRNA reads efficiently all four proline codons. If this tRNA in such a mutant contains ho ${ }^{5} \mathrm{U}$ instead of $\mathrm{cmo}^{5} \mathrm{U} 34$, a clear reduction in growth rate caused by the hypo-modification is observed (Näsvall et al. 2004). Furthermore, a mutant lacking the G34-containing tRNA ${ }_{\mathrm{GGG}}^{\text {Pro }}$ and thus having the $\mathrm{cmo}^{5} \mathrm{U} 34-$ and C34-containing tRNAs has a significant growth rate reduction in conjunction with hypo-modification of the wobble nucleoside in tRNA cro5UGG $_{\text {Pro }}$ (Näsvall et al. 2004). Based on these data and the theoretical prediction that $\mathrm{cmo}^{5} \mathrm{U} 34$ reads $\mathrm{U}$-ending codons (but not C-ending codons) (Yokoyama et al. 1985), we suggested that the reason for the observed phenotypes of the various mutants being deficient in $\mathrm{tRNA}^{\text {Pro }}$ and $\mathrm{cmo}^{5} \mathrm{U}$ was the slower reading of mainly the $\mathrm{U}$ - and $\mathrm{C}$ - ending proline codons (Näsvall et al. 2004). To verify this suggestion, we measured the A-site selection rates on each of the four proline codons. Lack of $t R N A_{\mathrm{CGG}}^{\mathrm{Pro}}$ and $\mathrm{tRNA} \mathrm{GGG}_{\mathrm{GG}}^{\mathrm{Pro}}$ leads to a large reduction in the rate of reading all four proline codons (Fig. 8, cf. LT2 and $\Delta$ proKL). This is not surprising, since the two missing tRNAs together make up about twothirds of the total proline tRNA pool (Dong et al. 1996) and should normally read most of the CCC, CCU, and CCG codons. Similarly to the alanine tRNA (Fig. 7), the largest effect of hypo-modification of tRNA ${ }_{\text {cmosUGG }}^{\text {Pro }}$ (Fig. 8, cf. LT2 and $c m o B 2$ and $\triangle$ proKL and $c m o B 2 \Delta$ proKL) seems to be a reduced rate of reading CCG. We also measured the effect of not having $\mathrm{cmo}^{5} \mathrm{U}$ on the A-site selection rates in mutants only lacking the C34-containing tRNA ${ }_{\text {CGG }}^{\text {Pro }}$ (proK<>frt). In two separate experiments, the rate of reading the CCG codon in the $c m o B 2$ mutant was reduced by $42 \%$ and $39 \%$, respectively (data not shown), further strengthening our observations that $\mathrm{cmo}^{5} \mathrm{U} 34$ is important for recognizing the G-ending proline codon.

\section{DISCUSSION}

In this study, we show that the function of the modified nucleoside $\mathrm{cmo}^{5} \mathrm{U} 34$ is different from what has previously been hypothesized and that the impact on hypomodification of the wobble position is different in different $\mathrm{cmo}^{5} \mathrm{U} 34$-containing tRNAs. According to a theoretical model, $\mathrm{cmo}^{5} \mathrm{U}$ is predicted to allow reading of U-ending codons (Yokoyama et al. 1985). This model was based on how the modification $\left(\mathrm{cmo}^{5}\right.$ or $\left.\mathrm{mo}^{5}\right)$, by interacting with the $5^{\prime}$-phosphate, affects the equilibrium between two different conformations ( $\mathrm{C} 2^{\prime}$-endo and $\mathrm{C}^{\prime}$-endo) of the ribose moiety of synthetic nucleotides in solution. 5Hydroxy uridine would not be able to make this interaction and would thus have decoding properties similar to uridine, which should only read A- and G-ending codons according to the wobble hypothesis (Crick 1966). The model did not explain why some $\mathrm{cmo}^{5} \mathrm{U}$-containing tRNAs can read C-ending codons, and, in fact, it was predicted that a $\mathrm{cmo}^{5} \mathrm{U}-\mathrm{C}$ pair would be impossible due to steric repulsion between ribose 34 and ribose 35 (Yokoyama et al. 1985). Moreover, this model would predict that a tRNA having ho ${ }^{5} \mathrm{U}$ in place of $\mathrm{cmo}^{5} \mathrm{U}$ would have a dramatically reduced rate of reading U-ending (and probably also Cending in the cases where it does happen) codons, while the rates of reading the A- and G-ending codons should not be

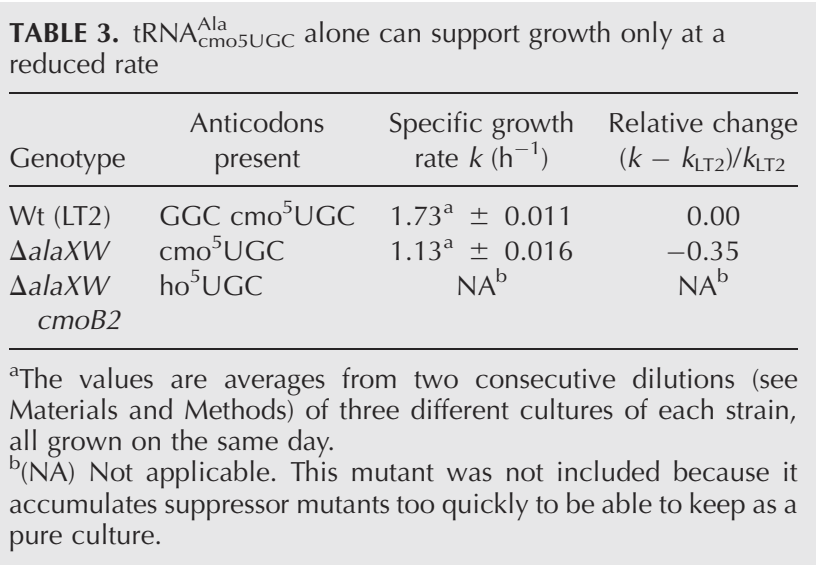




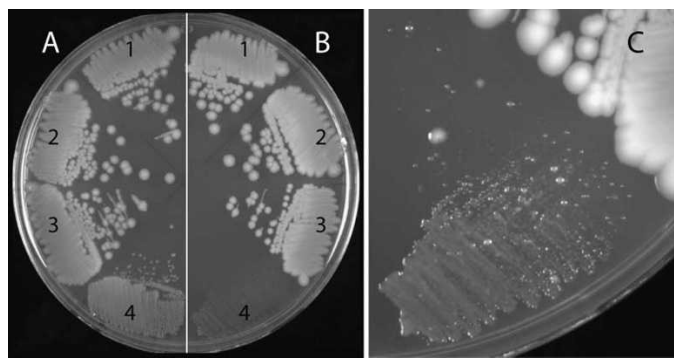

FIGURE 6. Overexpression of hypo-modified $\mathrm{TRNA}_{\mathrm{cmo5UGC}}^{\mathrm{Ala}}$ from plasmid p70 can partially restore growth of a $\triangle$ alaXW $\mathrm{cmoB} 2$ mutant. (A) Growth of (sector 1) LT2/p70 (wild-type); (sector 2) cmoB2<> kan/p70; (sector 3) $\Delta a l a X W / p 70$; and (sector 4) $\Delta a l a X W$ cmoB2 $<>$ $k a n / \mathrm{p} 70$ after $27 \mathrm{~h}$ at $37^{\circ} \mathrm{C}$ on an LA + tetracycline plate. The relative colony diameters (after 16 h) were (LT2/p70) $1.0 \pm 0.05$; $(\mathrm{cmoB} 2 / \mathrm{p} 70)$ $0.96 \pm 0.04$; and $(\Delta$ alaXW/p70) $0.92 \pm 0.07$. The colonies of $\Delta$ alaXW $c m o B 2 / p 70$ were visible but too small to measure. (B) Same as in $A$, but the strains do not contain any plasmid, and the plate is LA without any antibiotic. The relative colony diameters (after $16 \mathrm{~h}$ ) were (LT2) $1.0 \pm 0.07$; $(\mathrm{cmoB} 2) 1.0 \pm 0.01$; and $(\Delta a l a X W) 0.71 \pm 0.04$. At the time of the size measurements, no single colonies of the $\Delta$ alaXW cmoB2 mutant had appeared, but after $27 \mathrm{~h}$, very tiny colonies $(<0.1$ $\mathrm{mm}$ in diameter) as well as some faster-growing colonies (still too small to be clearly visible in the picture) could be seen. (C) Sector 4 of the plate in $B$, but after $75 \mathrm{~h}$. The absolute majority of the colonies of the $\triangle a l a X W$ cmoB2 mutant were still $<0.4 \mathrm{~mm}$ in diameter, while a few larger colonies ranging in sizes between $\sim 0.5$ and $2 \mathrm{~mm}$ were visible.

too much affected. However, our results do not support such a hypothesis, since the largest effect of hypo-modification of three tested tRNAs is on the rate of reading Gending codons, while the effects (if any) on C- and Uending codons are minor. This leads us to question the validity of the above model and suggests an alternative molecular mechanism for the decoding by $\mathrm{cmo}^{5} \mathrm{U}$.

Interestingly, the effects on the growth rates or viability when removing all other tRNA isoacceptors for the different amino acids are quite different. One extreme is the $\mathrm{cmo}^{5} \mathrm{U}$-containing threonine tRNA, which cannot at all support growth of a mutant lacking the G34-containing threonine isoacceptor (Table 1). This is similar to previously reported data for codon recognition by $\mathrm{cmo}^{5} \mathrm{U}$ containing (or mo ${ }^{5} \mathrm{U}$-containing) leucine (Nishiyama and Tokuda 2005; Sørensen et al. 2005) and serine (Takai et al. 1999) tRNAs. The $\mathrm{cmo}^{5} \mathrm{U}$-containing valine and alanine tRNAs can support growth of mutants lacking the corresponding G34-containing isoacceptors (Tables 2, 3), although the growth rates of such mutants are reduced compared to a wild-type strain. At the other extreme is the $\mathrm{cmo}^{5} \mathrm{U} 34$-containing proline isoacceptor, which supports growth at a rate indistinguishable from a wild-type strain even when both the G34- and C34-containing proline isoacceptors are missing (Näsvall et al. 2004). These dramatic differences between the different tRNAs could be the result of tRNAs having different relative efficiencies of recognizing one or more of their specific codons.
Alternatively, the expression of the $\mathrm{cmo}^{5} \mathrm{U} 34$-containing $\mathrm{tRNA}_{\mathrm{cmo5UGG}}^{\text {Pro }}$ could be high enough relative to the codon usage to allow efficient decoding even in the absence of the other proline tRNAs. However, among the $\mathrm{cmo}^{5} \mathrm{U}$ containing alanine, valine, and proline tRNAs, the proline tRNA is the least abundant relative to the codon usage (Table 4). Thus, codon usage and tRNA levels alone cannot explain the differences in phenotypes we observe.

Comparing the relative rates of A-site selection for the different $\mathrm{cmo}^{5} \mathrm{U} 34$-containing proline, valine, and alanine tRNAs when they are the only isoacceptors present (Fig. 5, $\Delta$ valVW; Fig. 7, $\Delta$ alaXW; Fig. 8, $\Delta$ proKL) the A-, G-, and $\mathrm{U}$-ending codons were recognized at similar rates, while the rates of recognizing the $\mathrm{C}$-ending alanine and valine codons are much lower (about fourfold lower than the other codons). In all cases, the rates at the A-ending codons were lower in the strains lacking the other isoacceptors than in the wild type. This was expected, as the remaining tRNAs have to read more of the codons that are normally also read by the other isoacceptors, leading to fewer tRNAs available to read the A-ending codon. In vitro a slightly lower rate of recognition was also observed toward the GCC (Ala) codon compared to the GCA (Ala) codon (Kothe and Rodnina 2007). However, tRNA $A_{\text {cmosUgG }}^{\text {Pro }}$ recognized the C-ending codon almost as efficiently as the other proline codons (Fig. $8)$, which could partly explain why the mutant $(\Delta$ proL proK<>frt) lacking the G34- and C34-containing proline isoacceptors has no apparent growth phenotype. One feature differentiating the anticodon loop in the $\mathrm{cmo}^{5} \mathrm{U}$ containing proline tRNA from the anticodon loops in the other tested tRNAs is the presence of four consecutive purines (G35-G36- ${ }^{1} \mathrm{G} 37-\mathrm{A} 38$ ). As purine-purine stacking is the most stable stacking interaction (Saenger 1984), this may lead to an exceptionally stable anticodon loop through

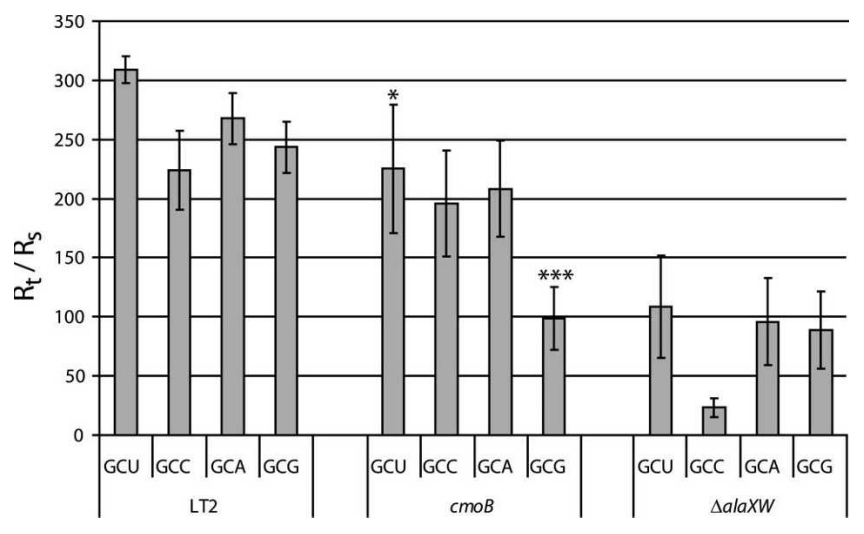

FIGURE 7. A-site selection rates at alanine (GCN) codons. The asterisks ${ }^{*}$ ) indicate values from the $c m o B 2$ mutant that are different from the control (LT2), as determined by a student's $t$-test [two sample, equal variance; $\left.\left({ }^{*}\right) p<0.05,\left({ }^{* *}\right) p<0.0005\right]$. All values from the $\Delta$ alaXW mutant are significantly different from LT2 $(p<0.0005)$. The values are averages from four experiments. 


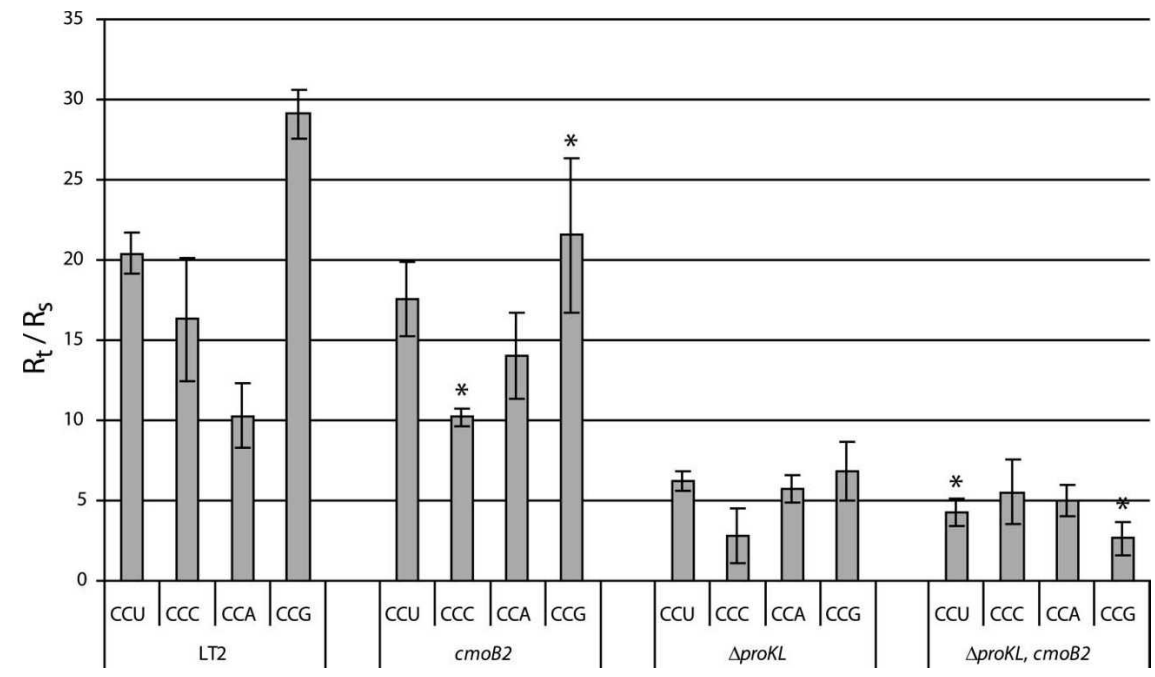

FIGURE 8. A-site selection rates at proline $(\mathrm{CCN})$ codons. The asterisks $\left.{ }^{*}\right)$ indicate values from the $c m o B 2$ mutant that are different from the control (LT2), as determined by a student's $t$-test [two sample, equal variance; $\left(^{\star}\right) p<0.05$ ]. All values for the $\Delta p r o L$ proK $<>$ frt and $\Delta p r o L$ proK $<>$ frt $c$ moB2 $<>$ frt mutants are significantly different from LT2 $(p<0.01)$. The values are averages from at least three experiments. For simplicity, $\Delta$ proL proK $<>$ frt is written $\Delta$ proKL.

extensive stacking of these bases, perhaps contributing to the efficiency of decoding the CCC codon by tRNA $\mathrm{RmosUGG}_{\text {Pro }}^{\text {Pro }}$

Combining the lack of the G34-containing (and C34containing) isoacceptors with hypo-modification $\left(\right.$ ho ${ }^{5} \mathrm{U} 34$ instead of $\left.\mathrm{cmo}^{5} \mathrm{U} 34\right)$ of the wobble nucleoside in the remaining isoacceptors also has different effects on the growth rates of the different mutants. All three mutants with only the $\mathrm{cmo}^{5} \mathrm{U}$-containing isoacceptors left in the respective family codon boxes $(\Delta$ proL proK $<>$ frt, $\Delta$ alaXW, and $\Delta$ valVW) have significantly reduced growth rates when combined with a $c m o B$ mutation (Tables 1, 3; Näsvall et al. 2004), but the severity of the synergistic phenotypes is very different. The $\triangle a l a X W$ cmoB2 mutant is virtually impossible to keep as a pure culture without accumulation of faster-growing suppressors (Fig. 6). The nature of the suppressors that accumulated in the $\triangle a l a X W \mathrm{cmoB} 2$ and $\Delta v a l V W$ mutants was not examined in detail, but at least some of them segregated into small and large colonies, indicating that they may be amplifications of the tRNA genes (data not shown). As both mutants were suppressed by expressing more of the remaining tRNA (Figs. 4 and 6), it is likely that amplification of the genes encoding these tRNAs would account for some of the suppressors. The effects of hypo-modification on the $\Delta$ proL proK $<>f r t$ and the $\Delta$ valVW mutants seem to be similar (although the $\Delta$ valVW mutant is very slow growing even in the presence of $\mathrm{cmo}^{5} \mathrm{U} 34$ ) (Fig. 4). Comparing the effects of having ho ${ }^{5} \mathrm{U}$ in place of $\mathrm{cmo}^{5} \mathrm{U}$ on the A-site selection rate for the different tRNAs (Figs. 5, 7, 8, cf. LT2 and cmoB2; Fig. 8, cf. $\triangle$ proKL and $\triangle$ proKL $\mathrm{cmoB2}$ ), the only codons where we observed significant differences in all three family boxes are at the G-ending codons. The largest effect is at the
G-ending alanine codon. Taken together, the data from the A-site selection assays indicate that the extreme phenotype of the $c m o B 2 \Delta a l a X W$ mutant probably is a combination of very poor recognition of the GCC codon due to the lack of the G34-containing alanine isoacceptor and the reduced efficiency of recognizing the GCG codon caused by the modification deficiency. In addition to the decreases in the selection rates at the G-ending codons, we also observed decreased rates on the Cending valine and proline codons and the U-ending alanine and proline codons. The effect of $\mathrm{cmo}^{5} \mathrm{U}$ deficiency on the ability of the $\Delta$ proL proK<>frt and $\Delta$ valvW mutants to recognize their corresponding G-ending codons is not as large as for the $\Delta a l a X W$ mutant, which could be an explanation of why the different mutants have such different growth phenotypes. There may be several reasons why $\mathrm{cmo}^{5} \mathrm{U}$ apparently is more important for the function of $\mathrm{tRNA}_{\text {cmosuGC }}^{\mathrm{Ala}}$ than it seems

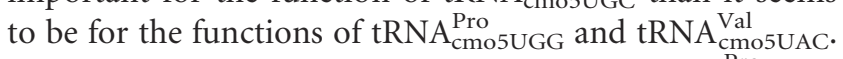
One might be that other features present in $\mathrm{RNA}_{\mathrm{cmos} \text { Gro }}^{\text {Pro }}$ and tRNA ${ }_{\text {cmosUAC }}^{\mathrm{Val}}$ but absent in tRNA $\mathrm{AmosUGC}_{\text {cma }}^{\mathrm{Ala}}$ contribute to their efficient decoding. One candidate for such a feature would be the modification of position 37 (immediately $3^{\prime}$ of the anticodon). tRNA ${ }^{\text {Pro }}$ has $\mathrm{m}^{1} \mathrm{G} 37$ (Kuchino et al. 1984), and tRNA ${ }^{\text {Val }}$ has $m^{6} A 37$ (Kimura et al. 1971), while tRNA $^{\text {Ala }}$ has an unmodified adenosine at position 37 (Lund and Dahlberg 1977). $\mathrm{m}^{1} \mathrm{G} 37$ has previously been

\begin{tabular}{|c|c|c|c|}
\hline Codon N(III) & Val & Ala & Pro \\
\hline U & $15.5^{\mathrm{a}}$ & $12.7^{\mathrm{a}}$ & $7.2^{\mathrm{a}}$ \\
\hline C & $18.2^{\mathrm{a}}$ & $29.1^{\mathrm{a}}$ & $6.9^{\mathrm{a}}$ \\
\hline A & $11.4^{\mathrm{a}}$ & $12.9^{\mathrm{a}}$ & $5.8^{\mathrm{a}}$ \\
\hline G & $25.1^{\mathrm{a}}$ & $42.8^{\mathrm{a}}$ & $24.7^{\mathrm{a}}$ \\
\hline Total & $70.3^{\mathrm{a}}$ & $97.6^{a}$ & $44.5^{\mathrm{a}}$ \\
\hline \multicolumn{4}{|l|}{ tRNA N34 } \\
\hline G & $4.0-7.2 \mu \mathrm{M}^{\mathrm{b}}$ & $2.0-3.6 \mu \mathrm{M}^{\mathrm{b}}$ & $2.3-4.0 \mu \mathrm{M}^{\mathrm{b}}$ \\
\hline $\mathrm{cmo}^{5} \mathrm{U}$ & $11-20 \mu \mathrm{M}^{\mathrm{b}}$ & $10-21 \mu \mathrm{M}^{\mathrm{b}}$ & $1.8-2.6 \mu \mathrm{M}^{\mathrm{b}}$ \\
\hline $\mathrm{C}$ & - & - & $2.4-3.5 \mu \mathrm{M}^{\mathrm{b}}$ \\
\hline \multicolumn{4}{|c|}{$\begin{array}{l}\text { a Codon usage is expressed as the number of each codon found per } \\
1000 \text { codons in coding sequences. Data from the codon usage } \\
\text { database (Nakamura et al. 2000) were re-calculated after removing } \\
\text { data from other sources than the published genomic sequence of } \\
\text { Salmonella typhimurium strain LT2. } \\
\text { bThe tRNA concentrations are the lowest and highest values } \\
\text { reported by Dong et al. (1996) from an E. coli K12 strain grown } \\
\text { at different growth rates. }\end{array}$} \\
\hline
\end{tabular}


demonstrated to be important for the A-site selection rate at all four proline codons ( $\mathrm{Li}$ et al. 1997). As the effects on growth rates of some of the mutants appear to be larger than one would expect from the changes in the A-site selection rates, it is possible that part of the growth phenotypes are due to defects in a stage of the translation elongation cycle other than the A-site selection. We have previously shown that having ho ${ }^{5} \mathrm{U}$ instead of $\mathrm{cmo}^{5} \mathrm{U}$ in $\mathrm{tRNA}_{\mathrm{cmo} \text { U UGG }}^{\text {Pro }}$ actually leads to decreased +1 frameshifting at CCC codons (Qian et al. 1998; Näsvall et al. 2004), which is why we do not think frameshifting in such a mutant reaches high enough levels to cause the observed growth-rate reduction.

It should be noted that there are organisms that have only a U34-containing tRNAs to read all four codons in some or all of the family codon boxes encoding Ser, Pro, Thr, Ala, Val, and Leu. Bacillus subtilis have only one proline tRNA (containing mo $0^{5} \mathrm{U} 34$ ) (Yamada et al. 2005), while it has two (mo5 ${ }^{5} 34$ and G34) or three $\left(\mathrm{mo}^{5} \mathrm{U} 34\right.$, G34, and C34) tRNAs in the other five boxes (Sprinzl and Vassilenko 2005). Certain intracellular parasites, like the Mollicutes (to which the Mycoplasmas belong), have very small, A/T-rich genomes with a reduced number of tRNA genes compared to free-living bacteria. Some of these use only U34-containing tRNAs in all these boxes, while the others have additional G34-, C34-, or A34-containing tRNAs in some of the serine, threonine, alanine, valine, or leucine boxes (for review, see De Crécy-Lagard et al. 2007). The codon usages of these organisms are very strongly biased toward A- and U-ending codons. The modification status of tRNAs from most of these organisms are unknown, but at least Mycoplasma capricolum and Mycoplasma mycoides have unmodified uridines at the wobble position. This may indicate that during their reductive evolution, the Mollicutes (distantly related to Bacillus) have lost the genes required to synthesize $\mathrm{mo}^{5} \mathrm{U}$, and have unmodified U34. As these bacteria use U34containing tRNAs to read primarily $\mathrm{A}$ - and U-ending codons, while they use C- and G-ending codons very rarely, this suggests that U34-containing tRNAs in the family codon boxes are unexpectedly efficient at reading U-ending codons, while this requirement may not be relevant for the rarely used G- and C-ending codons. This may be an exception enabled by special features of the ribosomes and/ or tRNAs from these highly specialized organisms, but it may also be a general rule for U34-containing tRNAs in other organisms as well. In fact, completely unmodified E. coli $\mathrm{tRNA} \mathrm{AGA}_{\mathrm{UGA}}^{\mathrm{Ser}}$ (which normally has $\mathrm{cmo}^{5} \mathrm{U} 34$ ) is capable of reading UCA and UCU in an in vitro translation system, but UCG is very poorly translated unless the wobble nucleoside is modified to $\mathrm{mo}^{5} \mathrm{U}$ (Takai et al. 1999). With this in mind, perhaps the unknown gene(s) encoding the enzyme(s) responsible for making ho ${ }^{5} \mathrm{U} 34$ from U34 in tRNA is essential for Salmonella and E. coli even in strains with the full complement of tRNAs, as the U34-containing alanine and valine tRNAs may require at least $\mathrm{ho}^{5} \mathrm{U}$ in order to recognize their G-ending codons efficiently enough to support growth.

Relevant to the coding capacities in Mollicutes is the "two out of three" decoding model, which states that the third position of the codon-anticodon interaction can be disregarded, as long as the interactions in the first two positions are strong (Lagerkvist 1978). This would apply to codons where the first two positions form G-C pairs (Pro, Ala, Arg, and Gly) but not to codons forming only A-U pairs (such as the Phe/Leu, Ile/Met, Tyr/Stop, and Asn/Lys mixed codon boxes). The two out of three model is supported by in vitro translation experiments in which the E. coli $\mathrm{cmo}^{5} \mathrm{U}$-containing alanine and valine tRNAs could incorporate the respective cognate amino acids at all four of their codons even in the presence of a competing cognate tRNA (Mitra et al. 1979; Samuelsson et al. 1980). The relative efficiency of the $\mathrm{cmo}^{5} \mathrm{U}$-containing tRNA in reading the four alanine and valine codons in the presence of the cognate tRNA is similar to our results obtained using the A-site selection assay in cells with only the fully modified $\mathrm{cmo}^{5} \mathrm{U}$-containing tRNA present to read all four codons (Figs. 5, 7). Lagerkvist assumed that the efficient reading of U-ending codons was caused by the presence of $\mathrm{cmo}^{5} \mathrm{U}$, while the less efficient reading of C-ending codons was regarded as two-out-of-three reading that did not involve an interaction at the third position. However, in vivo (Figs. 5, 7, 8) the hypo-modified derivatives were less efficient to read the G-ending and sometimes the U- or Cending codons, although the extent of the reductions at the C- and U-ending codons may be masked by the presence of the competing G34-containing tRNAs. Thus, the modification of the wobble base may contribute to the decoding efficiency even at C-ending codons and cannot be disregarded as suggested by the two out of three model. However, as we have no mutant that has unmodified U34, we cannot conclusively say if alanine, valine, or proline tRNA in such a mutant would still read U- or C-ending codons. Moreover, the fact that the Leu and Thr family boxes cannot be decoded by a single tRNA (Table 1; Nishiyama and Tokuda 2005; Sørensen et al. 2005) is not consistent with the two out of three decoding model. Why the $c 0^{5} \mathrm{U}$-containing Ala and Pro tRNAs can read C-ending codons but the Leu, Thr, and Ser tRNAs cannot may be related to the stability of the first two base pairs in the codon-anticodon complex (Ala and Pro make two G-C pairs, whereas Leu, Thr, and Ser make only one G-C pair). Still, it is unclear why $\mathrm{RNA}_{\text {cmosUAC }}^{\mathrm{Val}}$ can read all four codons (although not efficiently enough to support normal growth) when it also makes only one G-C pair (Fig. 5; Table 2).

In his wobble hypothesis, Crick predicted that U34 in tRNA would be able to form a wobble pair with G(III) in the mRNA (Crick 1966), with two hydrogen bonds between U34 and G(III). In order to allow formation of such a base pair, either U34 has to be displaced toward the major 
groove or G(III) has to be displaced toward the minor groove of the codon-anticodon mini-helix (a move of $\sim 2.5$ $\AA$ for one of the glycosidic bonds compared to a WatsonCrick base pair) (Fig. 9B; Crick 1966). It is unlikely that G(III) would be allowed to move, since its movement is restricted by its interactions with residues in the ribosomal 30S subunit (Ogle et al. 2001; Murphy et al. 2004). If U34 would move the entire distance required to form a U-G wobble pair, it would be unable to make a stacking interaction with the base in position 35 of the tRNA (Murphy et al. 2004), which could perhaps lead to poor recognition of G-ending codons by tRNAs with unmodified U34. Weixlbaumer et al. (2007) have recently solved the crystal structures of Thermus thermophilus $70 \mathrm{~S}$ ribosomes containing an $\mathrm{ASL}_{\mathrm{cmo5UAC}}^{\mathrm{Val}}$ (with the modifications $\mathrm{cmo}^{5} \mathrm{U} 34$ and $\left.\mathrm{m}^{6} \mathrm{~A} 37\right)$ bound to the four Val codons in the A-site. One interesting feature of the $\mathrm{cmo}^{5} \mathrm{U}-\mathrm{G}$ base pair is that it has standard Watson-Crick geometry rather than the expected wobble geometry (Fig. 9). This means that the 4-carbonyl group of $\mathrm{cmo}^{5} \mathrm{U} 34$ has to be in the rare enol form rather than the normal keto form and that the base pair makes three hydrogen bonds (Fig. 9B). Hillen et al. (1978) showed that $\mathrm{mo}^{5} \mathrm{U}$ has a shifted keto-enol equilibrium compared to uridine and $h 0^{5} \mathrm{U}$. Our data showing that tRNAs with $\mathrm{cmo}^{5} \mathrm{U} 34$ are significantly more efficient than tRNAs with ho ${ }^{5} \mathrm{U}$ at reading $\mathrm{G}$-ending codons are consistent with the observed crystal structure and predict that $\mathrm{cmo}^{5} \mathrm{U} 34$ is, indeed, in the enol form. In all four of these structures, the
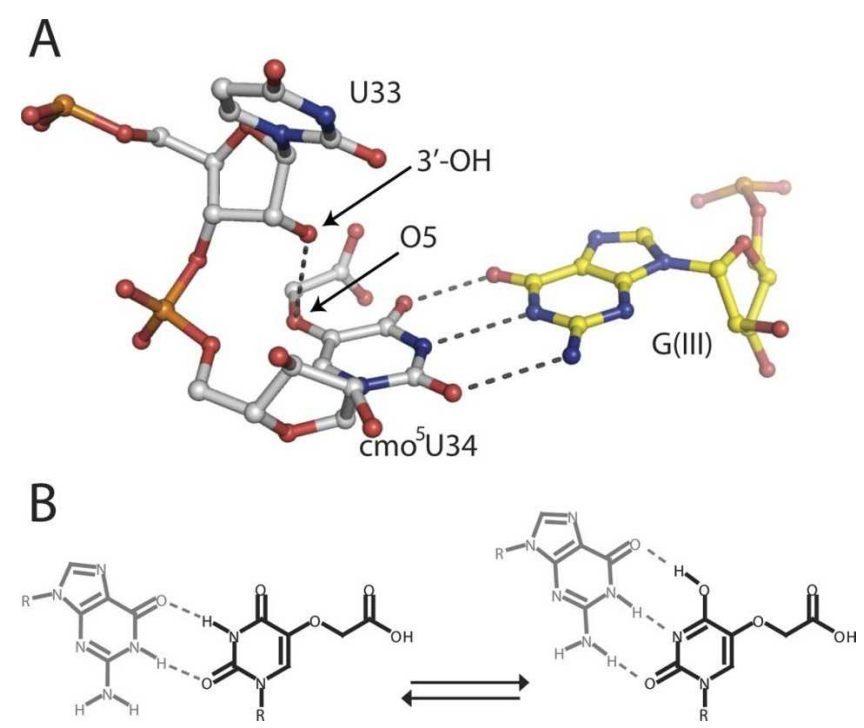

FIGURE 9. (A) The $\mathrm{cmo}^{5} \mathrm{U} 34-\mathrm{G}(\mathrm{III})$ base pair seen in the crystal structure solved by Weixlbaumer et al. (2007) (Protein Databank accession code 2UU9). The hydrogen bond between the 2'-OH of $\mathrm{U} 33$ and the $\mathrm{O} 5$ ether oxygen of $\mathrm{cmo}^{5} \mathrm{U} 34$ is indicated. (B) Keto-enol tautomerization of $\mathrm{cmo}^{5} \mathrm{U}$. (Left) The keto tautomer of $\mathrm{cmo}^{5} \mathrm{U}$ (black), forming a wobble pair with $\mathrm{G}$ (gray) as predicted by Crick. (Right) The enol tautomer of $\mathrm{cmo}^{5} \mathrm{U}$ (black), engaged in a base pair with $\mathrm{G}$ (gray). The geometry of the $\mathrm{cmo}^{5} \mathrm{U}-\mathrm{G}$ pair is the same as for a Watson-Crick (A-U or G-C) base pair. ether oxygen (O5) of the modification forms a hydrogen bond to the $2^{\prime}-\mathrm{OH}$ of U33 (Fig. 9A). This leads to a more constrained anticodon than if the wobble uridine would have been unmodified (Weixlbaumer et al. 2007), with the wobble nucleoside "locked" in position close to where it would be in a Watson-Crick base pair. The $\mathrm{cmo}^{5} \mathrm{U}-\mathrm{U}$ and $\mathrm{cmo}^{5} \mathrm{U}-\mathrm{C}$ pairs in the structures only form one hydrogen bond between the codon and anticodon bases (Weixlbaumer et al. 2007). Part of the stabilization needed to allow these pairs may come from the observed hydrogen bond between the $\mathrm{O} 5$ of $\mathrm{cmo}^{5} \mathrm{U} 34$ and the $2^{\prime}-\mathrm{OH}$ of $\mathrm{U} 33$. The $\mathrm{cmo}^{5} \mathrm{U}-\mathrm{U}$ pair may be further stabilized by interactions with $16 \mathrm{~S}$ rRNA, whereas the $\mathrm{cmo}^{5} \mathrm{U}-\mathrm{C}$ pair may be slightly destabilized by poor stacking between $\mathrm{C}$ (III) and its 5'-base (Weixlbaumer et al. 2007). These differences between the $\mathrm{cmo}^{5} \mathrm{U}-\mathrm{U}$ and $\mathrm{cmo}^{5} \mathrm{U}-\mathrm{C}$ pairs may explain why the Cending codons are poorly recognized by the $\mathrm{cmo}^{5} \mathrm{U}$ containing alanine and valine tRNAs, while the U-ending codons are recognized efficiently (Figs. 5, 7). Weixlbaumer et al. also point out that the carboxyl group of $\mathrm{cmo}^{5} \mathrm{U} 34$ is close enough to the oxygen of the 4-carbonyl group of $\mathrm{U}(\mathrm{III})$ to be able to form a hydrogen bond if the carboxyl group is protonated (Weixlbaumer et al. 2007). This would provide even further stability to the $\mathrm{cmo}^{5} \mathrm{U}-\mathrm{U}$ pair but not to the $\mathrm{cmo}^{5} \mathrm{U}-\mathrm{C}$ pair. In such a case, the hypo-modified ho ${ }^{5}$ 34-containing tRNAs in a $c m o B$ mutant (lacking the carboxyl group) would be affected in their reading of U-ending codons. Since we see no large effect on the rates of reading U-ending codons, our data do not support this suggestion. Another important observation in these structures is that in all four pairs, the ribose of $\mathrm{cmo}^{5} \mathrm{U} 34$ adopts the $3^{\prime}$-endo conformation, and the modification does not interact with its $5^{\prime}$-phosphate as predicted by Yokoyama et al. (1985).

Based on the structures discussed above (Fig. 9; Weixlbaumer et al. 2007) and our in vivo data, we suggest that the function of $\mathrm{cmo}^{5} \mathrm{U} 34$ (and $\mathrm{mo}^{5} \mathrm{U} 34$ ) may be dual: Firstly, the ether oxygen (or the hydroxyl of ho ${ }^{5} \mathrm{U}$ ) stabilizes the anticodon loop in a conformation where the wobble uridine is locked in position to form a base pair with Watson-Crick geometry. This leads to sufficient stabilization to compensate for the poor interactions between $\mathrm{cmo}^{5} \mathrm{U} 34$ and $\mathrm{U}(\mathrm{III})$ or $\mathrm{C}(\mathrm{III})$. Secondly, the rest of the modification $\left(-\mathrm{CH}_{3}\right.$ in $\mathrm{mo}^{5} \mathrm{U}$ or $-\mathrm{CH}_{3} \mathrm{COOH}$ in $\mathrm{cmo}^{5} \mathrm{U}$ ) stabilizes the enol form of the wobble nucleoside, promoting a nonstandard U34-G(III) base pair.

\section{MATERIALS AND METHODS}

\section{Bacteria and growth conditions}

The strains and plasmids used are listed in Table 5. All Salmonella strains are derivatives of Salmonella enterica serovar Typhimurium strain LT2. As solid rich medium, TYS (10 g of Trypticase peptone, $5 \mathrm{~g}$ of yeast extract, $5 \mathrm{~g}$ of $\mathrm{NaCl}$, and $15 \mathrm{~g}$ of agar per 
TABLE 5. Salmonella enterica serovar Typhimurium and Escherichia coli strains and plasmids

\begin{tabular}{|c|c|c|}
\hline Strain & Relevant genotype & Source/Reference \\
\hline \multicolumn{3}{|c|}{ Salmonella enterica serovar Typhimurium } \\
\hline GT3258* & LT2 & \\
\hline GT1796 & (TT10186) trp2482::MudA & \\
\hline GT6315 & pKD46/LT2 & \\
\hline GT6648 & $\operatorname{thr} T<>$ kan & This study \\
\hline GT6647 & thrV $<>$ kan & This study \\
\hline GT6683 & thrW $<>$ kan & This study \\
\hline GT6940 & thrV $<>f r t$ & This study \\
\hline GT6925 & thrT $<>$ frt & This study \\
\hline GT6926 & thrW $<>f r t$ & This study \\
\hline GT6300* & $\Delta v a l V W$ & This study \\
\hline GT6971 & $\Delta$ valVW cmoB2<>kan & This study \\
\hline GT6972 & $\Delta v a l V W$ cmoB2<>frt & This study \\
\hline GT7365* & $\Delta a l a X W$ & This study \\
\hline GT6856* & $c m o B 2<>f r t$ & Näsvall et al. (2004) \\
\hline GT6902* & $\Delta$ proL proK<>frt & Näsvall et al. (2004) \\
\hline GT6914* & $\Delta$ proL proK<>frt cmoB2<>frt & Näsvall et al. (2004) \\
\hline GT6877* & proK<>frt & äsvall et al. (2004) \\
\hline GT6898* & $\mathrm{cmoB} 2<>$ frt proK< $<$ frt & This study \\
\hline \multicolumn{3}{|c|}{ Escherichia coli } \\
\hline GRB1371 & (S17-1) thi pro $h s d B$ hsdM $M^{+}$recA RP4-2-Tc::Mu-Km::Tn7 $\lambda$ pir & Simon et al. (1983) \\
\hline GRB1748 & pUST300(pDM4+ salaXW)/GRB1371 & This study \\
\hline \multicolumn{3}{|l|}{ Plasmids } \\
\hline pDM4 & R6K $\gamma$ replication origin, $s a c B$ & Milton et al. (1996) \\
\hline pMAK705 & Ts replication origin & Hamilton et al. (1989) \\
\hline pKD46 & $\lambda$ red recombinase under araBAD promoter & Datsenko and Wanner (2000) \\
\hline pKD4 & Template plasmid for kanamycin resistance cassette & Datsenko and Wanner (2000) \\
\hline pKD3 & Template plasmid for chloramphenicol resistance cassette & Datsenko and Wanner (2000) \\
\hline pCP20 & FLP recombinase helper plasmid & Datsenko and Wanner (2000) \\
\hline pUST301 & $(\mathrm{pMAK} 705+\Delta \mathrm{val} / \mathrm{M})$ & This study \\
\hline PUST300 & $(\mathrm{pDM} 4+\Delta$ alaXW) & This study \\
\hline pJC27 & Pseudo-wild-type for A-site selection rate assays, $\mathrm{Cm}^{\mathrm{R}}$ & Curran and Yarus (1989) \\
\hline pJC-CCU & Test construct for A-site selection rate assays, $\mathrm{Cm}^{\mathrm{R}}$ & Curran and Yarus (1989) \\
\hline pJC-CCC & Test construct for A-site selection rate assays, $\mathrm{Cm}^{\mathrm{R}}$ & Curran and Yarus (1989) \\
\hline pJC-CCA & Test construct for A-site selection rate assays, $\mathrm{Cm}^{\mathrm{R}}$ & Curran and Yarus (1989) \\
\hline pJC-CCG & Test construct for A-site selection rate assays, $\mathrm{Cm}^{\mathrm{R}}$ & Curran and Yarus (1989) \\
\hline pJC-GUU & Test construct for A-site selection rate assays, $\mathrm{Cm}^{\mathrm{R}}$ & This study \\
\hline pJC-GUC & Test construct for A-site selection rate assays, $\mathrm{Cm}^{\mathrm{R}}$ & This study \\
\hline pJC-GUA & Test construct for A-site selection rate assays, $\mathrm{Cm}^{\mathrm{R}}$ & This study \\
\hline pJC-GUG & Test construct for A-site selection rate assays, $\mathrm{Cm}^{\mathrm{R}}$ & This study \\
\hline pJC-GCU & Test construct for A-site selection rate assays, $\mathrm{Cm}^{\mathrm{R}}$ & This study \\
\hline pJC-GCC & Test construct for A-site selection rate assays, $\mathrm{Cm}^{\mathrm{R}}$ & This study \\
\hline pJC-GCA & Test construct for A-site selection rate assays, $\mathrm{Cm}^{\mathrm{R}}$ & This study \\
\hline pJC-GCG & Test construct for A-site selection rate assays, $\mathrm{Cm}^{\mathrm{R}}$ & This study \\
\hline p815 & E. coli valU operon in pLG339, $\mathrm{Km}^{\mathrm{R}}$ & O'Connor (2002) \\
\hline pLG339 & Cloning vector, $\mathrm{Km}^{\mathrm{R}}$, $\mathrm{Tet}^{\mathrm{R}}$ & Stoker et al. (1982) \\
\hline p70 & E. coli aspT trpT ileU alaU thrV, Tet $^{\mathrm{R}}$ & Vila-Sanjurjo et al. (1999) \\
\hline
\end{tabular}

Strain numbers followed by an asterisk $\left(^{*}\right)$ indicate the strains used in the A-site selection assays.

liter) was used. As solid minimal medium, medium E (Vogel and Bonner 1956) containing $15 \mathrm{~g}$ of agar per liter and $0.2 \%$ glucose was used. As rich liquid medium, either LB or NAA $(0.8 \%$ Difco nutrient broth; Difco Laboratories) supplemented with the aromatic amino acids, aromatic vitamins, and adenine at concentrations as described previously (Davis et al. 1980) was used. For growth rate determination and assay of $\beta$-galactosidase activities, Rich MOPS (Neidhardt et al. 1977) was used. All growth was done at $37^{\circ} \mathrm{C}$. Antibiotics were used at the following concentrations:
Carbenicillin (Cb): $50 \mathrm{mg} / \mathrm{L}$; Kanamycin (Km): $100 \mathrm{mg} / \mathrm{L}$; Chloramphenicol (Cm): $12.5 \mathrm{mg} / \mathrm{L}$; Tetracycline (Tet): $15 \mathrm{mg} / \mathrm{L}$.

\section{Genetic procedures}

To transfer chromosomal markers or plasmids between Salmonella strains, transductions were performed as described previously (Davis et al. 1980) with a derivative of phage P22 containing the mutations HT105/I (Schmieger 1972) and int-201 (Scott et al. 
1975). Green indicator plates (Chan et al. 1972) were used for testing that the clones were phage free and phage sensitive.

\section{Molecular cloning procedures}

PCR fragments were purified from agarose gels using Wizard DNA clean-up resin (Promega) or directly using PCR kleen-spin (Bio-Rad). DNA sequencing was done using the DYEnamic ET terminator cycle sequencing kit (Amersham Pharmacia Biotech Inc.) or the BigDye Terminator v3.1 cycle sequencing kit (Applied Biosystems).

A 1.8-kb crossover PCR product containing the deletion of the alaXW operon (from $101 \mathrm{nt}$ upstream to $55 \mathrm{nt}$ downstream of alaXW) was generated as described by Link et al. (1997) and cloned into the suicide vector pDM4 (Milton et al. 1996). The plasmid (pUST300) was transformed into E. coli strain GRB1371, and the resulting strain (GRB1748) was used as donor in conjugation with the Salmonella strain GT1796 as recipient. Cointegrates were segregated by nonselective growth in LB supplemented with $5 \%$ sucrose. Sucrose-resistant segregants were screened by PCR to find clones carrying the alaXW deletion. To generate the valVW deletion, a $1.2-\mathrm{kb}$ crossover fragment containing a deletion of the valV and valW genes (from 6 nt upstream of valV to $28 \mathrm{nt}$ downstream of $v a l W$ ) was cloned into the temperature-sensitive suicide vector pMAK705 (Hamilton et al. 1989), generating pUST301. Cointegrates were obtained by growing at $44^{\circ} \mathrm{C}$ in the presence of chloramphenicol and segregated by growing nonselectively at $30^{\circ} \mathrm{C}$. Chloramphenicolsensitive segregants were screened by PCR to find clones carrying the valvW deletion on the chromosome.

We used the method described by Datsenko and Wanner (2000) to replace thrT, thrV, or thrW in strain GT6315 (an LT2 derivative with the $\lambda$-red recombinase plasmid pKD46) with the kanamycin resistance cassette amplified from plasmid pKD4 (Datsenko and Wanner 2000). The $<>k$ kan alleles were transferred by P22 transductions into strain LT2 before the FLP-recombinase helper plasmid pCP20 (Datsenko and Wanner 2000) was introduced to convert the $<>k$ kan alleles into $<>f r t$ alleles. To combine the different mutations, we used P22 lysates grown on strains containing the different $t h r<>k a n$ alleles as donors and cultures of strains containing the different $t h r<>f r t$ alleles as recipients in transductions, selecting $\mathrm{Km}^{\mathrm{R}}$ transductants (Table 1). To examine the presence of duplications in the rare transductants that appeared when trying to construct a thrT, thrV double mutant, 37 transductants (from transductions using thrT<>kan as donor and $t h r V<>$ frt as recipient), including clones that appeared after up to $72 \mathrm{~h}$ of incubation, were checked by PCR reactions designed to distinguish between the wild-type and $t h r T<>k a n$ alleles.

The $c m o B 2<>c a t$ allele was constructed to be identical to the cmoB2 $<>$ kan allele (Näsvall et al. 2004), except the chloramphenicol resistance cassette from plasmid pKD3 was used instead of the kanamycin resistance cassette from pKD4.

\section{Nomenclature of mutants}

An allele number followed by $<>$ and " $k a n$ " or "cat" indicates that the gene is replaced by the kanamycin or chloramphenicol resistance cassettes from plasmid pKD4 or pKD3, respectively (e.g., $c m o B 2<>k a n$ or $c m o B 2<>c a t$ ). After FLP-recombinasemediated removal of the cassette, the mutation is referred to with the same allele number, but with " $f r t$ " as description of the resulting scar sequence (e.g., $c m o B 2<>f r t$ ). The same allele number is also used for replacements where removal of two different FRT (Flp Recombinase Target sequence) flanked antibiotic resistance cassettes would produce an identical end result; hence $c m o B 2<>k a n, c m o B 2<>c a t$, and $c m o B 2<>$ frt have the same allele number. A " $\Delta$ " before a gene name refers to a precise deletion rather than a replacement (e.g., " $\Delta$ proL").

\section{Nomenclature of $t R N A s$}

In most cases, tRNAs are referred to with their cognate amino acid in three-letter code in superscript and with their anticodon sequence $\left(5^{\prime} \rightarrow 3^{\prime}\right)$ in subscript, i.e., $t R N A_{\text {cmo5UGC }}^{\text {Thr }}$ refers to a threonine tRNA with the anticodon $\mathrm{cmo}^{5} \mathrm{U} 34-\mathrm{G} 35-\mathrm{U} 36$. In some cases, the names of tRNA genes are followed by the wobble nucleoside of the corresponding tRNA within parentheses.

\section{Determination of growth rates}

Overnight cultures of the different strains were diluted to $\sim 0.05-$ $0.1 \mathrm{OD}_{420}$ units in pre-warmed medium and were pre-grown to $\mathrm{OD}_{420} \approx 1.0$. The cultures were then diluted to $\mathrm{OD}_{420} \approx 0.02-0.06$, and growth was monitored with a Shimadzu UV-1601 spectrophotometer at $420 \mathrm{~nm}$. When the OD of the cultures reached $\mathrm{OD}_{420} \approx 1.0$, they were again diluted into fresh pre-warmed medium. The cultures were judged to be in balanced growth when the growth rate determined after a dilution did not change more than $5 \%$ from what it was before dilution. We did not wait for the slow-growing $\Delta$ valVW (GT6300) or $\Delta$ valVW, cmoB2 (GT6972) mutants (Table 2) to reach balanced growth; instead, they were treated as follows: Overnight cultures of GT6300 or still growing cultures (with an $\mathrm{OD}_{420}$ below 1.0) of GT6972 were diluted once to $\mathrm{OD}_{420} \approx 0.05$, and growth was monitored until the OD again reached 1.0. Cultures of GT6300 were diluted once more, and monitoring continued until $\mathrm{OD}_{420} \approx 1.0$. Samples were withdrawn from the cultures and plated to estimate the proportion of faster-growing suppressor mutants. The data in Table 2 were calculated from cultures that contained $<5 \%$ suppressors at the end of the experiments. The specific growth rate is expressed as $k\left(\mathrm{~h}^{-1}\right)$, where $k=\ln 2 / g$ (where $g$ is the generation time in hours). Strain LT2 (wild-type) was always grown in parallel with the mutants to get a reference value for each experiment. Because of this, the values for LT2 in Tables 2 and 3 differ slightly from each other. To estimate the colony diameters reported in the legends for Figure 4 and Figure 6, the plates were photographed with a ChemiDoc XRS (Bio-Rad). Quantity One software (Bio$\mathrm{Rad}$ ) was used to measure the approximate width and height of square boxes manually fitted to surround each colony. The values are averages of five representative colonies (except the $c m o B 2<>$ kan mutant in Fig. 6B, sector 2, where only two colonies were sufficiently separated from other colonies). The average diameter of strain LT2 (containing the relevant plasmids) growing on the same plate was set to 1.0 .

\section{Determination of A-site selection rates}

Strains were grown overnight at $37^{\circ} \mathrm{C}$ in Rich MOPS medium supplemented with $12.5 \mu \mathrm{g} / \mathrm{mL}$ chloramphenicol, subcultured and grown to mid-log phase $\left(\mathrm{OD}_{600} \approx 0.5\right.$ using a Shimadzu UV-1201 spectrophotometer, corresponding to $\sim 2 \times 10^{8} \mathrm{CFU/}$ 
$\mathrm{mL}$ ). $\beta$-Galactosidase activity was measured as described by Miller (1972) (using the alternative method with chloroform and SDS instead of toluene to open the cells). ONPG was from Sigma. For each strain to be tested, at least two independent cultures were grown, and each strain was tested in at least three separate experiments. The plasmids for testing the alanine and valine codons were constructed by mutagenizing previously constructed plasmids (Curran and Yarus 1989) according to the protocol for the QuikChange Site-Directed Mutagenesis kit (Stratagene). The numbers presented in Figures 5, 7, and 8 are the A-site selection rates expressed as

$$
\frac{\mathrm{R}_{\mathrm{t}}}{\mathrm{R}_{\mathrm{S}}}=\frac{1}{\mathrm{~F}}-1
$$

where $\mathrm{F}$ is the frequency of frameshifting, determined by dividing the $\beta$-galactosidase activity of the test codon constructs with that of the pseudo-wild-type plasmid pJC27.

\section{ACKNOWLEDGMENTS}

This work was supported by grants from the Swedish Cancer Foundation (Project 680) and the Swedish Science Research Council (Project BU-2930). We are grateful to Drs. V. Ramakrishnan and A. Weixlbaumer (Cambridge, UK) for making their manuscript available prior to its publication and for the kind gift of the unpublished Figure 9A. We thank Gunilla Jäger for performing $\beta$ galactosidase assays and Tord Hagervall, Anders Byström, and Anders Esberg for critical reading of the manuscript.

Received July 16, 2007; accepted August 29, 2007.

\section{REFERENCES}

Chan, R.K., Botstein, D., Watanabe, T., and Ogata, Y. 1972. Specialized transduction of tetracycline resistance by phage P22 in Salmonella typhimurium. II. Properties of a high-frequencytransducing lysate. Virology 50: 883-898.

Crick, F.H.C. 1966. Codon-anticodon pairing. The wobble hypothesis. J. Mol. Biol. 19: 548-555.

Curran, J.F. and Yarus, M. 1989. Rates of aminoacyl-tRNA selection at 29 sense codons in vivo. J. Mol. Biol. 209: 65-77.

Datsenko, K.A. and Wanner, B.L. 2000. One-step inactivation of chromosomal genes in Escherichia coli K-12 using PCR products. Proc. Natl. Acad. Sci. 97: 6640-6645.

Davis, W., Botstein, D., and Roth, J.R. 1980. A manual for genetic engineering: Advanced bacterial genetics. Cold Spring Harbor Laboratory, Cold Spring Harbor, New York.

De Crécy-Lagard, V., Marck, C., Brochier-Armanet, C., and Grosjean, H. 2007. Comparative RNomics and Modomics in mollicutes: Prediction of gene function and evolutionary implications. IUBMB Life 59: 634-658.

Dong, H.J., Nilsson, L., and Kurland, C.G. 1996. Covariation of tRNA abundance and codon usage in Escherichia coli at different growth rates. J. Mol. Biol. 260: 649-663.

Gabriel, K., Schneider, J., and McClain, W.H. 1996. Functional evidence for indirect recognition of $\mathrm{G} \cdot \mathrm{U}$ in tRNA ${ }^{\text {Ala }}$ by alanyltRNA synthetase. Science 271: 195-197.

Hamilton, C.M., Aldea, M., Washburn, B.K., Babitzke, P., and Kushner, S.R. 1989. New method for generating deletions and gene replacements in Escherichia coli. J. Bacteriol. 171: 4617-4622.

Hillen, W., Egert, E., Lindner, H.J., Gassen, H.G., and Vorbruggen, H. 1978. 5-Methoxyuridine: The influence of 5-substituents on the
Keto-enol tautomerism of the 4-carbonyl group. J. Carbohydrates Nucleosides Nucleotides 5: 23-32.

Ishikura, H., Yamada, Y., and Nishimura, S. 1971. Structure of serine tRNA from Escherichia coli. I. Purification of serine tRNA's with different codon responses. Biochim. Biophys. Acta 228: 471-481.

Kimura, F., Harada, F., and Nishimura, S. 1971. Primary sequence of tRNA-Val-1 from Escherichia coli B. II. Isolation of large fragments by limited digestion with RNases, and overlapping of fragments to reduce the total primary sequence. Biochemistry 10: 32773283.

Kothe, U. and Rodnina, M.V. 2007. Codon reading by tRNA ${ }^{\text {Ala }}$ with modified uridine in the wobble position. Mol. Cell 25: 167-174.

Kuchino, Y., Yabusaki, Y., Mori, F., and Nishimura, S. 1984. Nucleotide sequences of three proline tRNAs from Salmonella typhimurium. Nucleic Acids Res. 12: 1559-1562. doi: 10.1093/nar/ 12.3.1559.

Lagerkvist, U. 1978. "Two out of three": An alternative method for codon reading. Proc. Natl. Acad. Sci. 75: 1759-1762.

Li, J.N., Esberg, B., Curran, J.F., and Björk, G.R. 1997. Three modified nucleosides present in the anticodon stem and loop influence the in vivo aa-tRNA selection in a tRNA-dependent manner. J. Mol. Biol. 271: 209-221.

Link, A.J., Phillips, D., and Church, G.M. 1997. Methods for generating precise deletions and insertions in the genome of wild-type Escherichia coli: Application to open reading frame characterization. J. Bacteriol. 179: 6228-6237.

Lund, E. and Dahlberg, J.E. 1977. Spacer transfer RNAs in ribosomal RNA transcripts of E. coli: Processing of 30 S ribosomal RNA in vitro. Cell 11: 247-262.

Miller, J.H. 1972. Experiments in molecular genetics. Cold Spring Harbor Laboratory, Cold Spring Harbor, New York.

Milton, D.L., O'Toole, R., Horstedt, P., and Wolf-Watz, H. 1996. Flagellin A is essential for the virulence of Vibrio anguillarum. J. Bacteriol. 178: 1310-1319.

Mitra, S.K., Lustig, F., Akesson, B., Axberg, T., Elias, P., and Lagerkvist, U. 1979. Relative efficiency of anticodons in reading the valine codons during protein synthesis in vitro. J. Biol. Chem. 254: 6397-6401.

Murphy, F.V., Ramakrishnan, V., Malkiewicz, A., and Agris, P.F. 2004. The role of modifications in codon discrimination by tRNA LUs LuU. Nat. Struct. Mol. Biol. 11: 1186-1192.

Nakamura, Y., Gojobori, T., and Ikemura, T. 2000. Codon usage tabulated from international DNA sequence databases: Status for the year 2000. Nucleic Acids Res. 28: 292. doi: 10.1093/nar/28.1.292.

Näsvall, S.J., Chen, P., and Björk, G.R. 2004. The modified wobble nucleoside uridine-5-oxyacetic acid in tRNA cro $_{\text {PrUGG }}$ promotes reading of all four proline codons in vivo. RNA 10: 1662-1673.

Neidhardt, F.C., Bloch, P.L., Pedersen, S., and Reeh, S. 1977. Chemical measurement of steady-state levels of ten aminoacyl-transfer ribonucleic acid synthetases in Escherichia coli. J. Bacteriol. 129: 378-387.

Nishiyama, K.I. and Tokuda, H. 2005. Genes coding for SecG and Leu2-tRNA form an operon to give an unusual RNA comprising mRNA and a tRNA precursor. Biochim. Biophys. Acta 1729: 166173.

O'Connor, M. 2002. Insertions in the anticodon loop of tRNA $_{1}^{\text {Gln }}($ sufG $)$ and tRNA ${ }^{\text {Lys }}$ promote quadruplet decoding of CAAA. Nucleic Acids Res. 30: 1985-1990. doi: 10.1093/nar/30.9.1985.

Oda, K., Kimura, F., Harada, F., and Nishimura, S. 1969. Restoration of valine acceptor activity by combining oligonucleotide fragments derived from a Bacillus subtilis ribonuclease digest of Escherichia coli valine transfer RNA. Biochim. Biophys. Acta 179: 97-105.

Ogle, J.M., Brodersen, D.E., Clemons Jr., W.M., Tarry, M.J., Carter, A.P., and Ramakrishnan, V. 2001. Recognition of cognate transfer RNA by the 30S ribosomal subunit. Science 292: 897902.

Phelps, S.S., Malkiewicz, A., Agris, P.F., and Joseph, S. 2004. Modified nucleotides in tRNA ${ }^{\text {Lys }}$ and RNAA $^{\text {Val }}$ are important for translocation. J. Mol. Biol. 338: 439-444. 
Qian, Q., Li, J.N., Zhao, H., Hagervall, T.G., Farabaugh, P.J., and Björk, G.R. 1998. A new model for phenotypic suppression of frameshift mutations by mutant tRNAs. Mol. Cell 1: 471-482.

Saenger, W. 1984. 6.6 Thermodynamic description of stacking interactions. Principles of nucleic acid structure, pp. 134-137. SpringerVerlag, New York.

Samuelsson, T., Elias, P., Lustig, F., Axberg, T., Fölsch, G., Åkesson, B., and Lagerkvist, U. 1980. Aberrations of the classic codon reading scheme during protein synthesis in vitro. J. Biol. Chem. 255: 4583-4588.

Schmieger, H. 1972. Phage P22-mutants with increased or decreased transduction abilities. Mol. Gen. Genet. 119: 75-88.

Scott, J.F., Roth, J.R., and Artz, S.W. 1975. Regulation of histidine operon does not require hisG enzyme. Proc. Natl. Acad. Sci. 72: 5021-5025.

Simon, R., Priefer, U., and Pühler, A. 1983. A broad host range mobilization system for in vivo genetic engineering: transposon mutagenesis in Gram negative bacteria. Biotechnology (N. Y.) 1: 784-791.

Sørensen, M.A., Elf, J., Bouakaz, E., Tenson, T., Sanyal, S., Björk, G.R., and Ehrenberg, M. 2005. Overexpression of a tRNA ${ }^{\text {Leu }}$ isoacceptor changes charging pattern of leucine tRNAs and reveals new codon reading. J. Mol. Biol. 354: 16-24.

Sprinzl, M. and Vassilenko, K.S. 2005. Compilation of tRNA sequences and sequences of tRNA genes. Nucleic Acids Res. 33: D139-D140. doi: 10.1093/nar/gki012.
Stoker, N.G., Fairweather, N.F., and Spratt, B.G. 1982. Versatile lowcopy-number plasmid vectors for cloning in Escherichia coli. Gene 18: $335-341$.

Takai, K., Okumura, S., Hosono, K., Yokoyama, S., and Takaku, H. 1999. A single uridine modification at the wobble position of an artificial tRNA enhances wobbling in an Escherichia coli cell-free translation system. FEBS Lett. 447: 1-4.

Vila-Sanjurjo, A., Squires, C.L., and Dahlberg, A.E. 1999. Isolation of kasugamycin resistant mutants in the $16 \mathrm{~S}$ ribosomal RNA of Escherichia coli. J. Mol. Biol. 293: 1-8.

Vogel, H.J. and Bonner, D.M. 1956. Acetylornithinase of Escherichia coli: Partial purification and some properties. J. Biol. Chem. 218: 97-106.

Weixlbaumer, A., Murphy, F.V., Dziergowska, A., Malkiewicz, A., Vendeix, F.A., Agris, P.F., and Ramakrishnan, V. 2007. Mechanism for expanding the decoding capacity of transfer RNAs by modification of uridines. Nat. Struct. Mol. Biol. 14: 498-502.

Yamada, Y., Matsugi, J., Ishikura, H., and Murao, K. 2005. Bacillus subtilis $\mathrm{RRN}^{\text {Pro }}$ with the anticodon mo5UGG can recognize the codon CCC. Biochim. Biophys. Acta 1728: 143-149.

Yokoyama, S., Watanabe, T., Murao, K., Ishikura, H., Yamaizumi, Z., Nishimura, S., and Miyazawa, T. 1985. Molecular mechanism of codon recognition by tRNA species with modified uridine in the first position of the anticodon. Proc. Natl. Acad. Sci. 82: 4905-4909. 

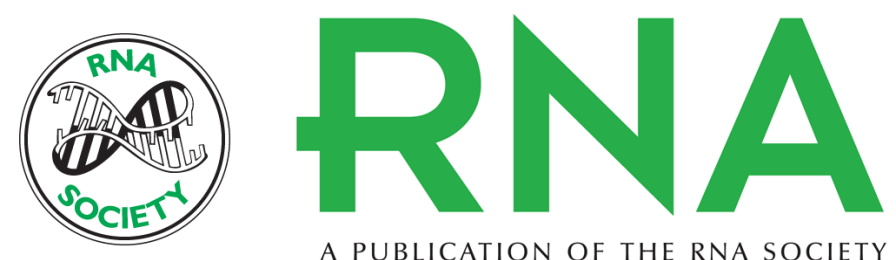

A PUBLICATION OF THE RNA SOCIETY

\section{The wobble hypothesis revisited: Uridine-5-oxyacetic acid is critical for reading of G-ending codons}

S. Joakim Näsvall, Peng Chen and Glenn R. Björk

RNA 2007 13: 2151-2164

References This article cites 42 articles, 14 of which can be accessed free at:

http://rnajournal.cshlp.org/content/13/12/2151.full.html\#ref-list-1

License

Email Alerting Receive free email alerts when new articles cite this article - sign up in the box at the Service top right corner of the article or click here. 